\title{
Research on Characteristics of Tracked Vehicle Steering on Slope
}

\author{
Yu Zhang $\mathbb{D}$, Mianhao Qiu $\mathbb{D}$, Xixia Liu $\mathbb{D}$, Jun Li $\mathbb{D}$, Haijun Song $\mathbb{D}$, Yue Zhai $\mathbb{D}$, \\ and Hongjuan Hu $\mathbb{D}$
}

Army Academy of Armored Forces, Beijing, China

Correspondence should be addressed to Xixia Liu; lxxljh@sina.com

Received 6 July 2020; Revised 19 November 2020; Accepted 5 January 2021; Published 31 January 2021

Academic Editor: He Chen

Copyright (c) $2021 \mathrm{Yu}$ Zhang et al. This is an open access article distributed under the Creative Commons Attribution License, which permits unrestricted use, distribution, and reproduction in any medium, provided the original work is properly cited.

\begin{abstract}
A special design is needed for an unmanned tracked vehicle (UTV) to meet the requirements of off-road environments and complex tasks. A loose surface is the main terrain for tracked vehicles in off-road driving. Slope steering is inevitable while driving in such conditions; hence, its performance is a major concern for tracked vehicles on loose terrain. This study investigates the slope steering performance of a tracked vehicle. An improved dynamic steering model is proposed when considering the shear stressshear displacement relation of soil at the track-ground interface. The influence of ground characteristics on the slope steering performance of a tracked vehicle is illustrated. The track slip rate is adopted as an index to evaluate the influence of typical vehicle structure parameters on the slope steering performance of a tracked vehicle. This study provides technical support for the design and optimization of UTV.
\end{abstract}

\section{Introduction}

Traditional unmanned vehicle design depends on the assembly of external parts and units to form a vehicle. Unmanned vehicle for various applications requires integrated design [1]. The core technology is to test the dynamic features of vehicles during the design phase by experimenting with sets of parameters that correspond to different terrain conditions. Off-road vehicles always experience uncertain longitudinal and lateral slips when running on soft and sloping terrain [2]. With outstanding climbing power enabling them to run in high-gradient terrains such as hills and mountains, unmanned tracked vehicles (UTVs) are extensively applied in fields such as firefighting [3], agriculture [4], and the military [5].

Unconventional modes of control are inevitable on complex terrain, such as driving across obstacles and steering on slopes, and these place special requirements on UTVs design. A UTV with special functions must be designed with insufficient experimental data and experience, depending on standard accessories and parts. This requires the prediction of vehicle performance and determination of a design plan based on modelling and simulation.
In the research of the dynamic performance of tracked vehicle slope steering, Zhang [6] studied the influence on tracked vehicle uniform steering of lateral and longitudinal gradients. Shi and Sun $[7,8]$ analysed the change rules and impact factors of the offset of the instantaneous steering centre (ISC) while a tracked vehicle steers on a slope, so as to indicate instability factors in steering. Qingdong [9] established a dynamic model of slope steering and analysed the offset of the ISC and the change rules of steering-required braking force and traction pull to determine how different steering radii and gradients impact steering stability and determined the factors causing steering instability. Considering the influence of track sliding and steering centrifugal force while running, Xue [10] established kinematic and dynamic models of slope steering based on the universal mechanism (UN) system change rule on parameters including steering radius, normal load, and dynamic tension. Based on terramechanics theory, Zhang [11] analysed the traction pull and resistance acting on a tracked mining vehicle while it steered and ran on extremely soft bottom material in the bathyal zone and formulated control strategies for its safety and stability while running on a slope. According to the change rules of steering performance parameters, Yue [12] reviewed steering performance on flat and hilly areas. 
Weifang [13] analysed the impact on steering performance of structural parameters including track width, track-ground contact length, gauge, and centre distance of front and rear track sets. Guoqiang [14] analysed the impact of width and length proportion, hinge joint location, and other factors on articulated tracked vehicle steering performance. Dong [15] analysed the effects of variations in track length, track width, vehicle width, and pressure centre height on the tractive forces of both tracks while an articulated tracked vehicle was steering.

From the above, we see that the slope steering dynamics model of a tracked vehicle has been intensively studied, and the relationship between the structural parameters and dynamic performance of tracked vehicle slope steering has been established. However, the influence of the characteristics of off-road ground on slope steering performance has not been studied.

Based on the dynamic model of tracked vehicle slope steering and its relation to the shear force-slip rate, we take the track slip rate as an index to judge the performance of vehicle slope steering. We take the tractive forces of both tracks of a UTV as indices to evaluate the slope steering performance.

When steering on a slope of the loose ground, the tracks of a UTV will slip or skid more easily. The theoretical and actual speed of both tracks can be acquired accurately in real time through sensor fusion $[16,17]$. Therefore, the slip rate can accurately evaluate the slope steering performance of a UTV.

According to the parameters of mass, tread, trackground contact length, height of centre of gravity, and track width, we compare the slope steering performance and analyse how changing structural parameters of a vehicle influence its steering performance, so as to provide technical support for the design of a UTV.

\section{Dynamical Model of Tracked Vehicle Slope Steering}

Figure 1 shows an azimuthal diagram of tracked vehicle slope steering. The first through fourth quadrants correspond to the uphill steering downside, downhill steering downside, downhill steering upside, and downhill steering upside. To calculate the longitudinal- and side-tilting grades under different positions will facilitate a better analysis. Figure 2 shows a force analytical diagram of tracked vehicle slope steering while the azimuth angle is in the first quadrant.

Figure 2 indicates the tracked vehicle slope steering at angle $\theta$, while the azimuth angle is $\varphi$, the equivalent longitudinal-tilting angle is $\alpha$, and the equivalent side-tilting grade is $\beta$, where

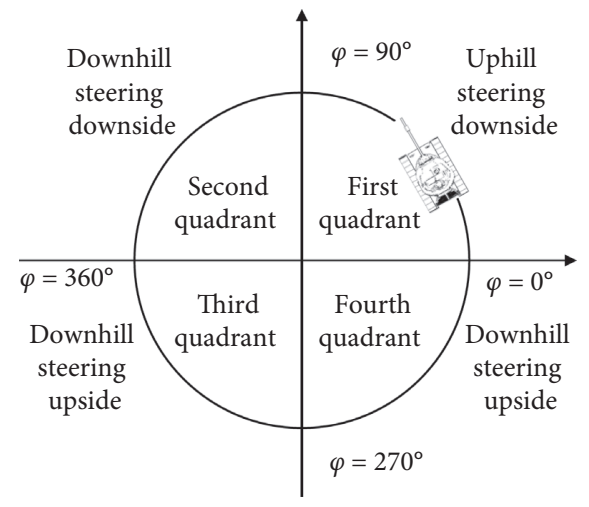

FIgURE 1: Azimuthal diagram of tracked vehicle slope steering.

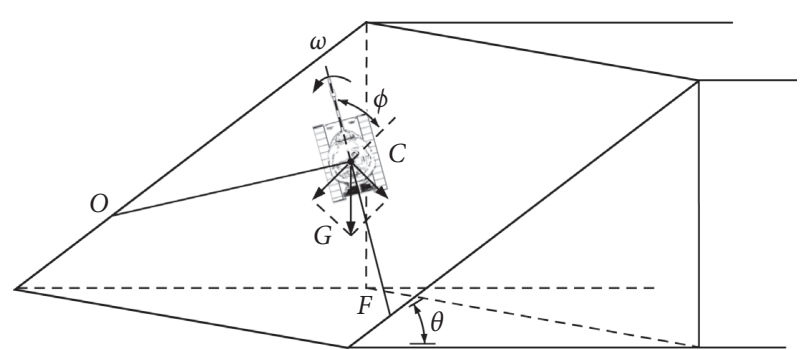

FIgUre 2: Force analytical diagram of tracked vehicle slope steering.

$$
\begin{aligned}
& \tan \alpha=\frac{G \sin \theta \cos \varphi}{\cos \theta}=\tan \theta \cos \varphi, \\
& \tan \beta=\frac{G \sin \theta \sin \varphi}{\cos \theta}=\tan \theta \sin \varphi .
\end{aligned}
$$

Under the impact of transverse and longitudinal forces, the pressure centre of normal counterforce deviates from the transverse and longitudinal orientations of the vehicle's horizontal centre to a certain extent when the tracked vehicle is slope steering. If the longitudinal and transverse offsets of the pressure centre are $x_{0}$ and $y_{0}$, respectively, then we can calculate

$$
\left\{\begin{array}{l}
X h_{g}=F x_{0}, \\
Y h_{g}=F y_{0},
\end{array}\right.
$$

where $h_{g}$ is the height of the vehicle's centre of gravity, $X=$ $G \sin \theta \cos \varphi$ and $Y=G \sin \theta \sin \varphi$.

$$
\begin{aligned}
& x_{0}=h_{g} \tan \alpha=h_{g} \tan \theta \cos \varphi, \\
& x_{0}=h_{g} \tan \beta=h_{g} \tan \theta \sin \varphi .
\end{aligned}
$$


The normal load of both side tracks of the track-ground contact area equals the equivalent superposition of the normal load on the longitudinal- and side-tilting slopes.
Hence, the normal load ladder diagram of the left- and rightside tracks is shown in Figure 3 and calculated as follows:

$$
\text { Inner track: }\left\{\begin{array}{l}
q_{q 1}=\frac{G \cos \theta}{2 L}\left(1-\frac{6 h_{g} \tan \theta \cos \varphi}{L}\right)+\frac{G \sin \theta \cos \varphi}{B L} h_{g}, \\
q_{h 1}=\frac{G \cos \theta}{2 L}\left(1+\frac{6 h_{g} \tan \theta \cos \varphi}{L}\right)+\frac{G \sin \theta \cos \varphi}{B L} h_{g}, \\
q_{p 1}=\frac{G \cos \theta}{2 L}+\frac{G \sin \theta \cos \varphi_{g} .}{B L} h_{g} \\
\text { Outer track: }\left\{\begin{array}{l}
q_{q 2}=\frac{G \cos \theta}{2 L}\left(1-\frac{6 h_{g} \tan \theta \cos \varphi}{L}\right)+\frac{G \sin \theta \cos \varphi}{B L} h_{g}, \\
q_{h 2}=\frac{G \cos \theta}{2 L}\left(1+\frac{6 h_{g} \tan \theta \cos \varphi}{L}\right)+\frac{G \sin \theta \cos \varphi}{B L} h_{g}, \\
q_{p 2}=\frac{G \cos \theta}{2 L}+\frac{G \sin \theta \cos \varphi}{B L} h_{g},
\end{array}\right.
\end{array}\right.
$$

where $q_{q}, q_{h}$, and $q_{p}$ are the normal loads of the front, rear, and centre point of track, respectively, and the subscripts 1 and 2 indicate the inner and outer track, respectively, the same below. $L$ is the contacted length of the track, and $B$ is the vehicle tread.
Figure 4 indicates the lateral resistance ladder diagram, the normal load while the instantaneous centre for the parts of the outer and inner tracks in contact with and sliding on the ground by unit length. $\lambda$ is the offset of the instantaneous steering centre. $Y$ is the lateral force acting on centre point $C$.

$$
\begin{array}{r}
q_{\lambda 1}=q_{p 1}+\left(q_{h 1}-q_{p 1}\right) \frac{2 \lambda}{L}=\frac{G \cos \theta}{2 L}+\frac{G \sin \theta \sin \varphi}{B L} h_{g}+\frac{6 \lambda G h_{g} \sin \theta \cos \varphi}{L^{3}}, \\
q_{\lambda 2}=q_{p 2}+\left(q_{h 2}-q_{p 2}\right) \frac{2 \lambda}{L}=\frac{G \cos \theta}{2 L}-\frac{G \sin \theta \sin \varphi}{B L} h_{g}+\frac{6 \lambda G h_{g} \sin \theta \cos \varphi}{L^{3}}, \\
\frac{1}{2} \mu\left(q_{q 1}+q_{\lambda 1}\right)\left(\frac{L}{2}+\lambda\right)+\frac{1}{2}\left(q_{q 2}+q_{\lambda 2}\right)\left(\frac{L}{2}+\lambda\right)
\end{array}
$$

Sort out

$24 \mu \lambda^{2} h_{g} \tan \theta \cos \varphi+4 \lambda L^{2}-6 h_{g} \tan \theta \cos \varphi L^{2}=\frac{2 L^{3} \tan \theta \sin \varphi}{\mu}$, when $\varphi=90^{\circ}$ and $\varphi=270^{\circ}, \cos \varphi=0$.

$$
\lambda=\frac{L}{2 \mu} \tan \theta \sin \varphi,
$$

when $\varphi=90^{\circ}$ and $\varphi \neq 270^{\circ}$,

$$
\lambda=-\frac{L^{2}}{12 h_{g} \tan \theta \cos \varphi} \pm \frac{1}{2} \sqrt{\left(\frac{L^{2}}{6 h_{g} \tan \theta \cos \varphi}\right)^{2}+L^{2}+\frac{L^{3} \tan \varphi}{3 \mu h_{g}}} .
$$




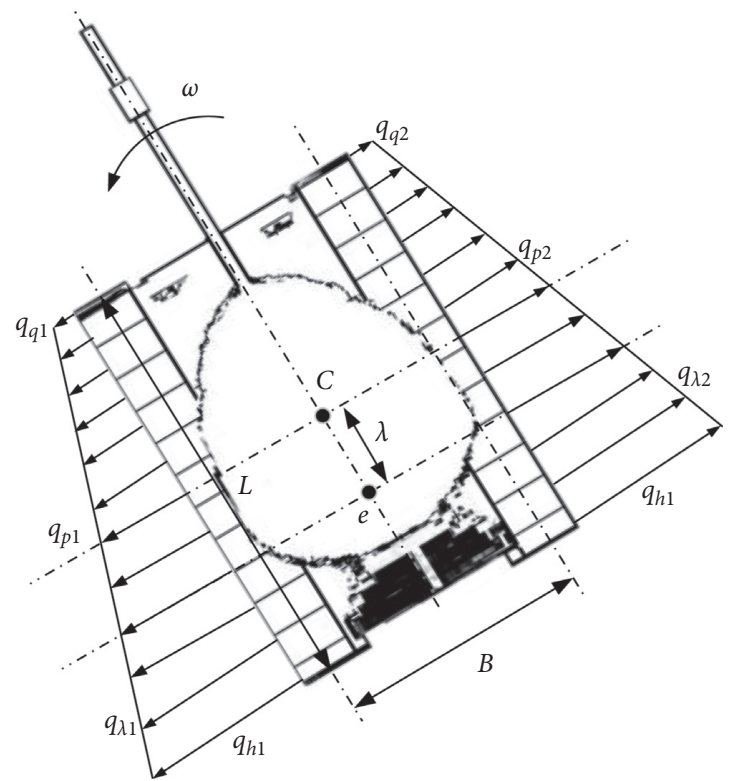

Figure 3: Normal load diagram of both tracks.

Steering resistance moment is equivalent to the moment acting on point $\mathrm{C}$ to the area of lateral resistance ladder diagram as follows:

$$
M_{\mu}=\frac{\mu G \cos \theta}{L}\left(\frac{L^{2}}{4}-3 h_{g} \tan \theta \cos \varphi \lambda+\lambda^{2}+\frac{4 \lambda^{3} h_{g} \tan \theta \cos \varphi}{L^{2}}\right) .
$$

With the traverse force, the external moments acting on the tracked vehicle include not only the steering resistance moment but also the simultaneous external moment to the centre generated by lateral force $Y$; hence, the integrated lateral external moment is

$$
M_{\mu}=\frac{\mu G \cos \theta}{L}\left(\frac{L^{2}}{4}-3 h_{g} \tan \theta \cos \varphi \lambda+\lambda^{2}+\frac{4 \lambda^{3} h_{g} \tan \theta \cos \varphi}{L^{2}}\right)-G \lambda \sin \theta \sin \varphi
$$

Figure 5 shows the external force acting on a tracked vehicle while slope steering. $F_{1}$ and $F_{2}$ are the braking force and traction pull, respectively, required by the inner and outer tracks while steering, and $R_{1}$ and $R_{2}$ represent the external motion resistance of both tracks.

If the tracked vehicle steering moves at a uniform speed, then a longitudinal balanced force and balanced moment acting on the horizontal level centre $\mathrm{C}$ are necessary and are related by

$$
\left\{\begin{array}{l}
F_{2}-F_{1}=R_{1}+R_{2}+X \\
\left(F_{2}+F_{1}\right) \frac{B}{2}=\left(R_{2}-R_{1}\right) \frac{B}{2}+M_{\mu s} .
\end{array}\right.
$$

The required braking force and traction pull of the inner and outer tracks while vehicle slope steering can be calculated as

$$
\left\{\begin{array}{l}
F_{1}=-R_{1}+\frac{M_{\mu s}}{B}-\frac{X}{2}, \\
F_{2}=R_{2}+\frac{M_{\mu s}}{B}-\frac{X}{2},
\end{array}\right.
$$

where $\quad R_{1}=\left((G \cos \theta / 2)+(G \sin \theta \sin \varphi / B) h_{g}\right) f \quad$ and $R_{1}=\left((G \cos \theta / 2)-(G \sin \theta \sin \varphi / B) h_{g}\right) f$.

Figures 6(a) and 6(b) show comparison graphs of the azimuth angle $\varphi$ of traction pull on the outer track and braking force on the inner track, respectively, while slope steering on grades of slope angles. 


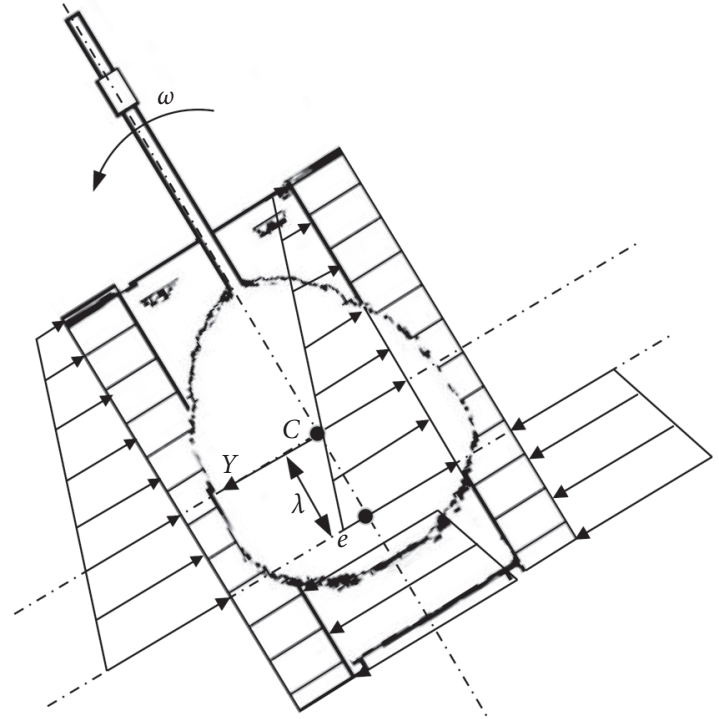

FIgURE 4: Lateral resistance diagram of both tracks.

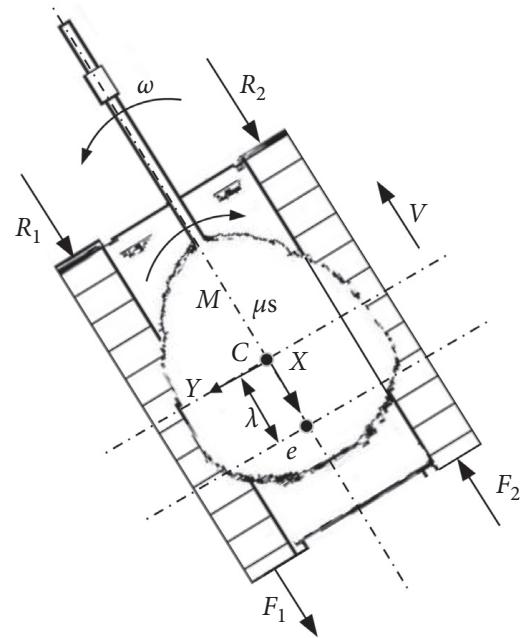

FIGURE 5: External force diagram of tracked vehicle slope steering.

Based on the theory of terramechanics, after the change rules of traction pull and braking force are calculated, the change rule of the slip rate can be calculated.

In terrains such as sand, saturated clay, fresh powder snow, and most disturbed soil, we adopt an exponential function as pointed out by Janosi and Hanamoto $[18,19]$ to describe the corresponding shear force-shear displacement relation as follows:

$$
\tau=\tau_{\max }\left(1-e^{-(j / K)}\right)=(c+\sigma \tan \Phi)\left(1-e^{-(j / K)}\right),
$$

where $\tau$ is shear force, $j$ is shear displacement, $c$ is soil cohesion, $\sigma$ is normal stress, $\Phi$ is the internal friction angle of the soil, $\tau_{\max }$ is the maximum shear strength, and $K$ is the shear deformation parameter.

The total shear force generated by the tracks is

$$
F=b \int_{0}^{L} \tau \mathrm{d} x=b \int_{0}^{L}(c+\sigma \tan \Phi)\left(1-e^{-(j / K)}\right) \mathrm{d} x,
$$

where and are the width and contacted length, respectively, of the track.

Figure 7 shows a relative movement diagram of the track and ground, where $j=V_{j} t, V_{j}$ is the track's relative slip velocity to the ground, and $V_{t}$ is the theoretical velocity of the track, which is equivalent to the product of the rotating speed of the sprocket, and the pitch radius of the sprocket, $c$. Therefore, we obtain

$$
j=\frac{V_{j} x}{V_{t}}=i x,
$$

where $i$ is the track slip rate, $x$ is the distance between one point on the track and the front end of the contact area, and

$$
F=b \int_{0}^{l}(c+\sigma \tan \Phi)\left(1-e^{-(i x / K)}\right) \mathrm{d} x .
$$

We establish the dynamical model and shear stress-shear displacement relationship of tracked vehicle slope steering using MATLAB. To correspond the equations (16) to the (12), the slip rate of both tracks can be resolved. When the slip rate exceeds the maximum, which indicates the terrain cannot provide enough force, it will cause complete slip on the track, finally leading to instability and loss of control. The track slip rate can be taken as an index to judge the performance of vehicle slope steering.

\section{Impact Analysis of Vehicle Working Conditions and Terrain Types on Steering Performance}

We selected five typical terrains: gault, snow, grit, Petawawa marsh, and LETE sand, with terrain parameters $[20,21]$ as shown in Table 1.

3.1. Impact of Gradient Angle on Tracked Vehicle Steering Performance on Slope. Figures 8(a) and 8(b) show the slip rate changeable curves of inner track steering at different slope angles on snow. With an increasing slope angle, the slip rate of the inner track gradually increases. When the slope angle reaches $15^{\circ}$ and the vehicle azimuth angle is between $155^{\circ}$ and $210^{\circ}$, the slip rate is over 1 , which causes a complete skid, so the steering action is not completed in the specified radius.

As Figures 9(a) and 9(b) indicate, the vehicle can implement circular steering with a larger gradient on gault terrain than on snow ground. When the angle of the gradient $\theta=21^{\circ}$, it will cause a complete slip or skid in the first and fourth quadrant which indicates that the tracked vehicle more easily slips and skids in the upslope phase. As the angle of gradient increases, the azimuth range related to complete slip and skid becomes larger.

The vehicle slope steering properties differ between the snow and gault terrain types. We analyse the track slip and skid conditions of the inner and outer tracks.

\subsection{Impact of Ground Characteristics on Tracked Vehicle Slope} Steering Performance. We selected the above five types of terrain on which to implement a simulation analysis, with the same angle of gradient, steering radius, and steering velocity. 


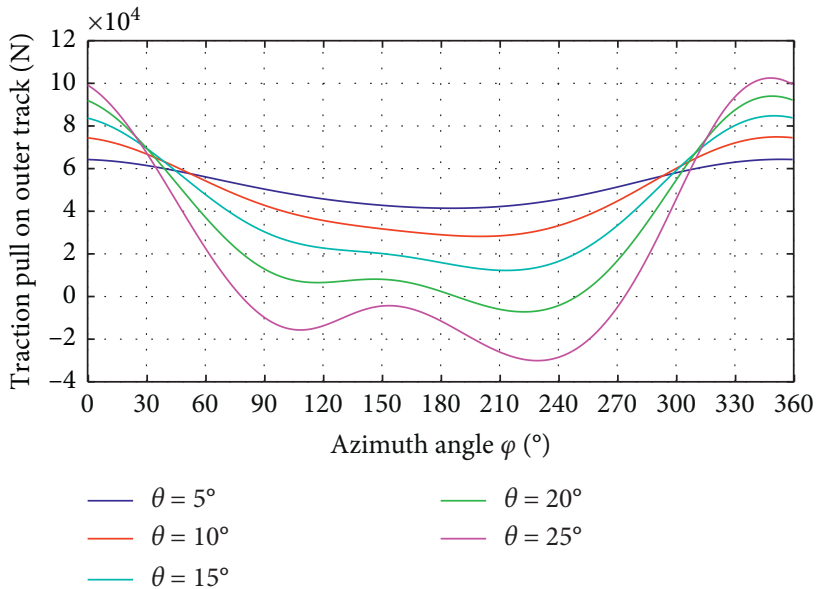

(a)

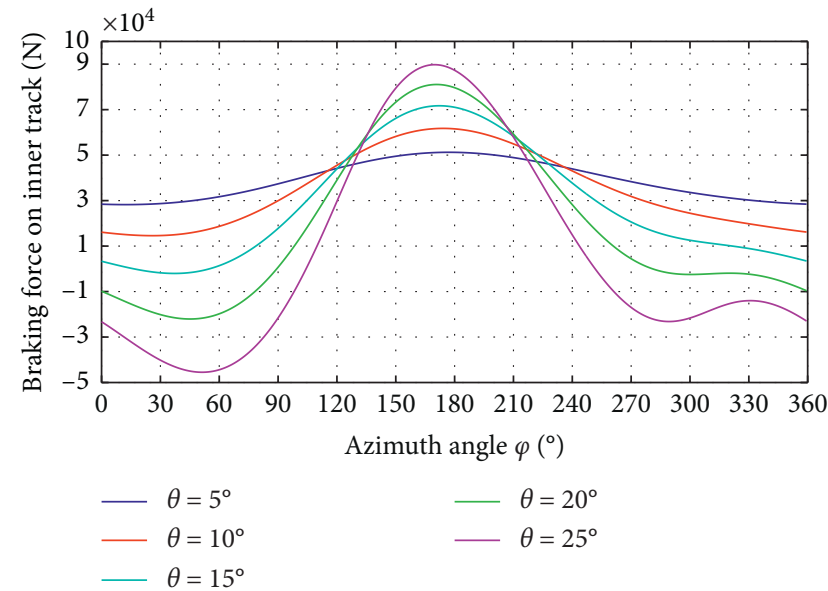

(b)

Figure 6: (a) Comparison graph of outer track traction pull at different slope angles. (b) Comparison graph of inner track braking force at different slope angles.

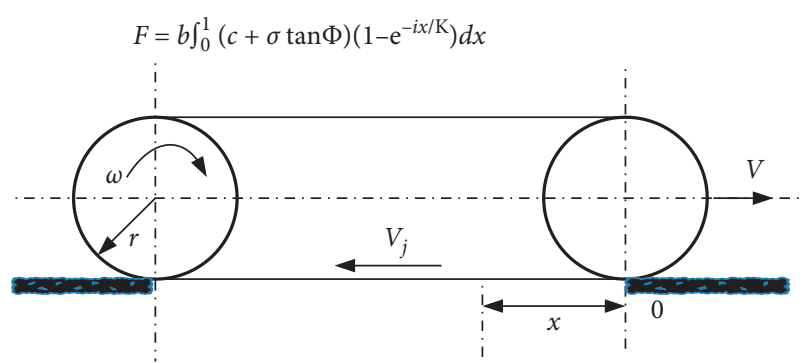

FIGURE 7: Relative movement diagram between track and ground.

TABLE 1: Five types of terrain parameters.

\begin{tabular}{lccc}
\hline Terrain type & $c(\mathrm{kPa})$ & $\varphi\left(^{\circ}\right)$ & $K(\mathrm{~cm})$ \\
\hline Gault & 68.92 & 34 & 0.6 \\
Snow & 6 & 20.7 & $2.5-5$ \\
Grit & 0 & 33 & 2.5 \\
Petawawa marsh & 2.8 & 39.4 & 3.1 \\
LETE sand & 1.3 & 31.1 & 1.2 \\
\hline
\end{tabular}

Figures 10(a) and 10(b) show the slip of the inner and outer tracks on the five types of terrain. Terrain with better cohesion, such as gault, enables vehicle slope steering with a larger angle of the gradient. For UTVs, terrain condition is necessary to make driving and control strategy. To ignore the impact of terrain conditions will lead to errors in planning and control that can prevent a steering action, or even cause instability and loss of control.

3.3. Impact of Steering Radius on Tracked Vehicle Steering Performance on Slope. With the angle of gradient $\theta=10^{\circ}$ and gault terrain, we performed simulations with steering radius $R=10 \mathrm{~m}, 20 \mathrm{~m}, 30 \mathrm{~m}, 40 \mathrm{~m}$, and $50 \mathrm{~m}$.

As Figures 11(a) and 11(b) show, as the steering radius increases, the inner and outer tracks' slip rates decrease. When the vehicle steers with a small radius, more power is needed from the terrain. Therefore, slope steering with a small radius can easily cause complete track slip and skid, which can lead to vehicle instability, loss of control, and even rollover.

\section{Impact of Structural Parameter on Tracked Vehicle Steering Performance on Slope}

We indicate the structural parameters of seven typical tracked vehicles in Table 2. We implemented a simulation analysis on slope steering performance, where the terrain type is Petawawa marsh, the angle of gradient $\theta=10^{\circ}$, and the steering radius $R=20 \mathrm{~m}$.

Figures 12(a) and 12(b) compare the slip rate of the inner and outer tracks of seven types of tracked vehicles when slope steering with specified radius. The diagram shows that tracked vehicles with different structural parameters have different inner and outer track slip rates when slope steering with the same gradient angle and steering radius conditions, and it is difficult to judge the exact impact of specified structural parameters on steering performance. The next, choose AV A as an example, angle of gradient $\theta=10^{\circ}$ and steering radius $R=20 \mathrm{~m}$, take the control variate method to select five structural parameters to the implement simulated analysis. The five structural parameters of vehicle mass, tread of track, track-ground contact length, height of vehicle centre of gravity, and track width impact the performance of tracked vehicle slope steering.

4.1. Vehicle Mass Impact on Tracked Vehicle Slope Steering Performance. We selected $m=5000 \mathrm{~kg}, m=15000 \mathrm{~kg}$, $m=25000 \mathrm{~kg}, m=35000 \mathrm{~kg}$, and $m=55000 \mathrm{~kg}$ for analysis, with simulation results shown in Figures 13(a) and 13(b).

As Figures 13(a) and 13(b) show that the vehicle slope steering with heavier mass, the track requires more power corresponding. For the outer track, the difference mainly exists in the first and fourth quadrants, and for the inner track in the second and third quadrants. Choosing the min and max values to evaluate the variation trend of curves, the 


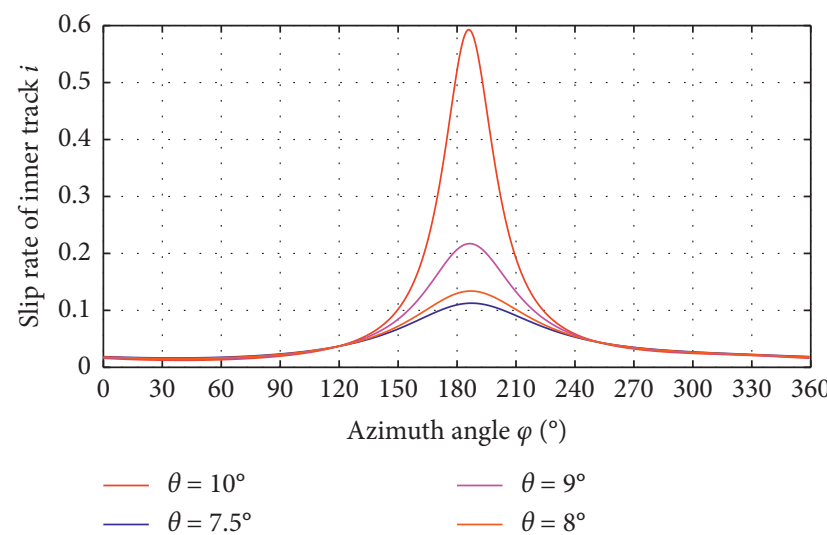

(a)

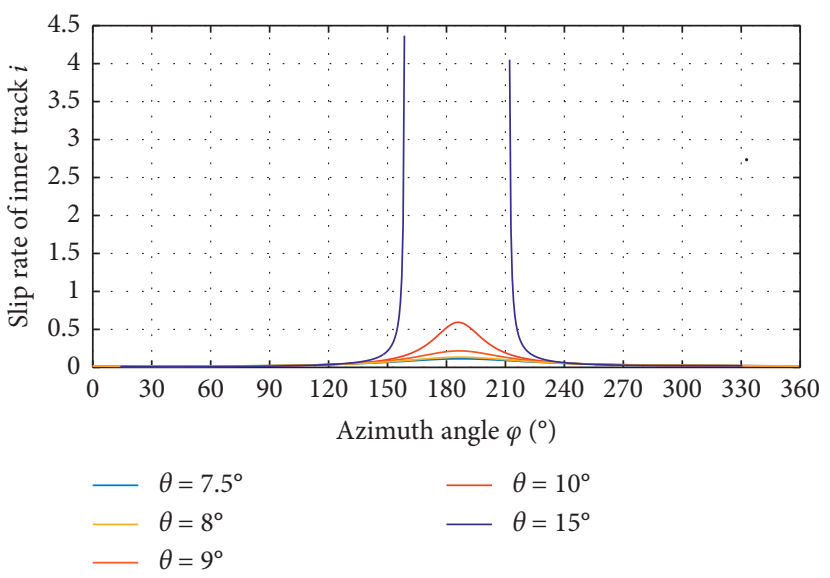

(b)

FIGURE 8: (a) Changes in slip rate of inner track of slope steering at different slope angles on snow. (b) Changes in slip rate of inner track of slope steering at different slope angles on snow.

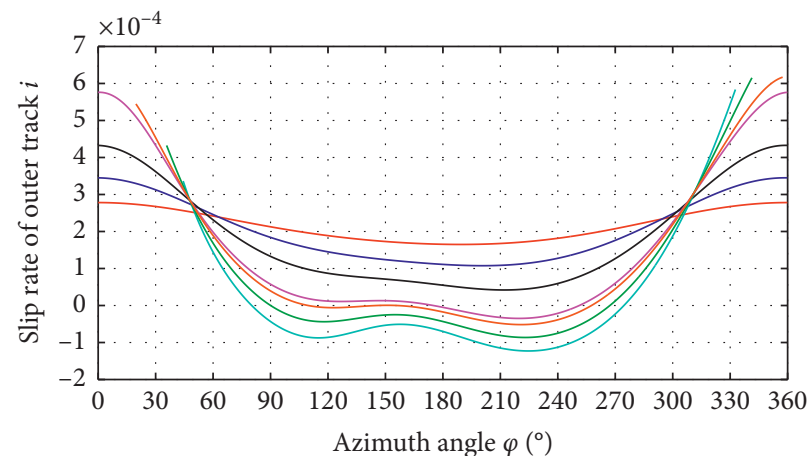

$\theta=5^{\circ}$

$\theta=10^{\circ}$

$-\theta=15^{\circ}$

$\theta=20^{\circ}$

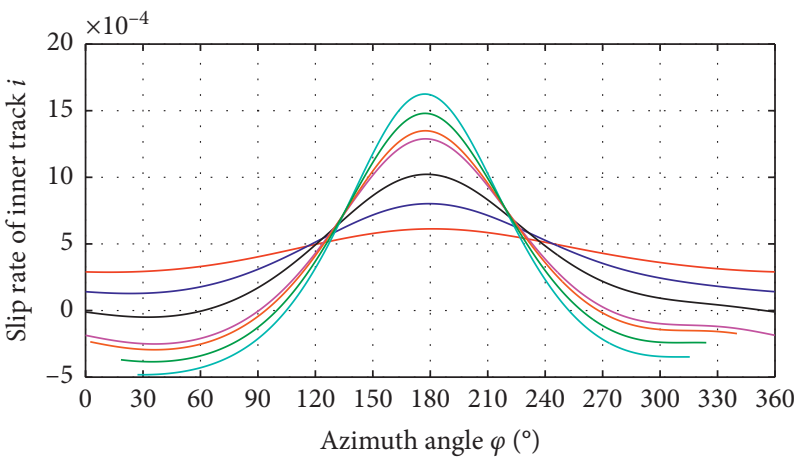

$-\theta=5^{\circ}$

$-\theta=10^{\circ}$

$-\theta=15^{\circ}$

$-\theta=21^{\circ}$

$-\theta=23^{\circ}$

- $\theta=25^{\circ}$

(a)

(b)

Figure 9: (a) Changes in slip rate of outer track of slope steering at different slope angles on gault. (b) Changes in slip rate of inner track of slope steering at different slope angles on gault.

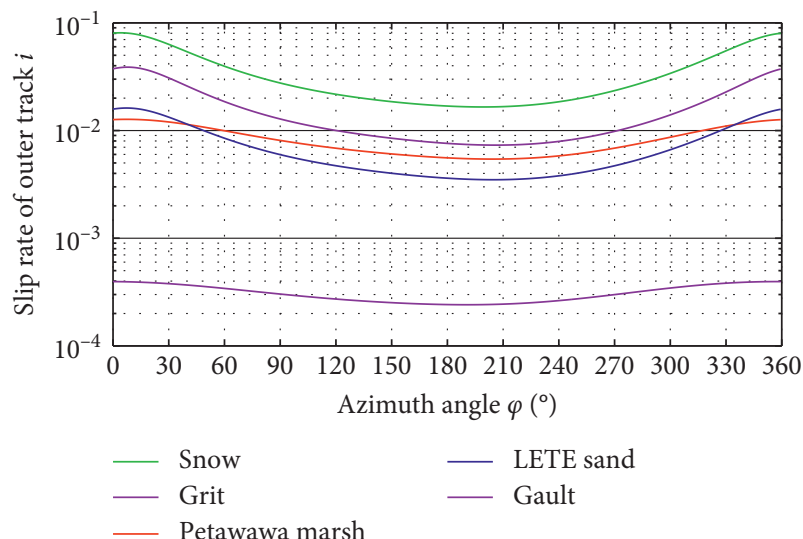

(a)

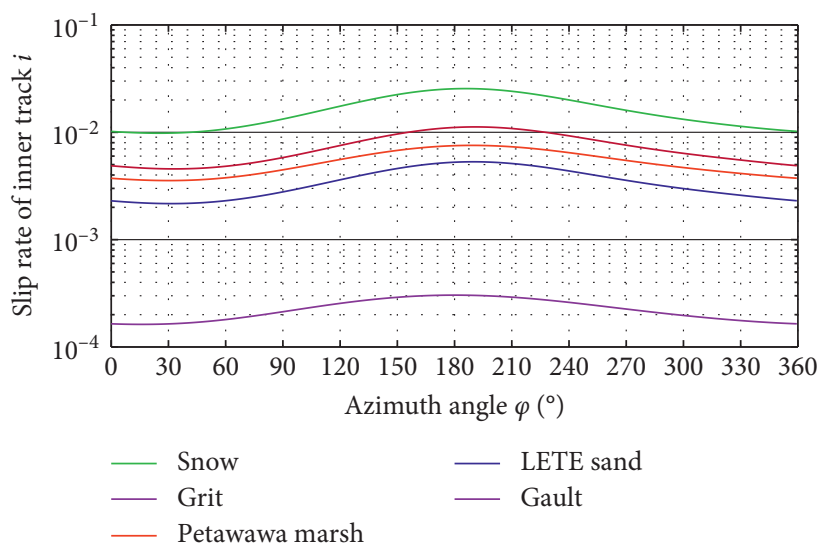

(b)

FIGURE 10: (a) Changes in slip rate of outer track of slope steering at different angles of gradient on five types of terrain. (b) Changes in slip rate of inner track of slope steering at different slope angles on five types of terrain. 


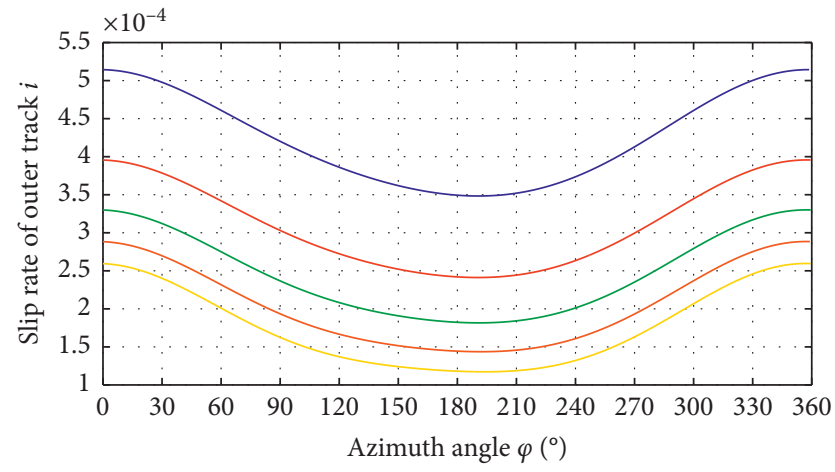

$\begin{aligned} R & =10 \mathrm{~m} \\ R & =20 \mathrm{~m} \\ R & =30 \mathrm{~m}\end{aligned}$

(a)
$R=40 \mathrm{~m}$

$R=50 \mathrm{~m}$

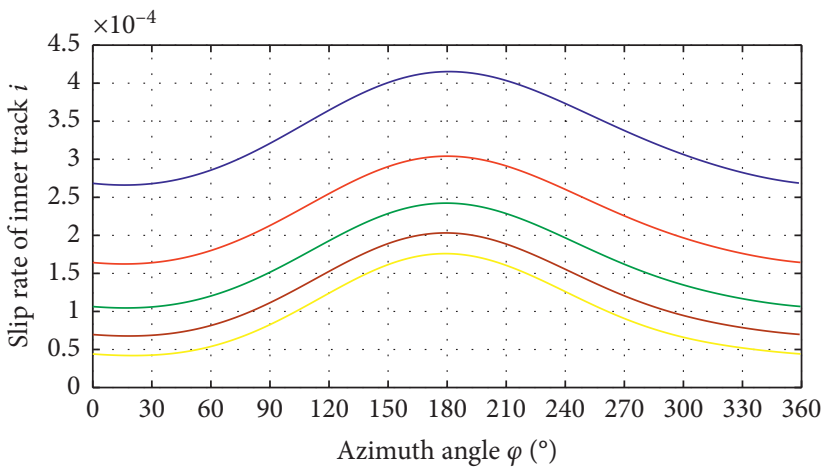

$\begin{aligned} R & =10 \mathrm{~m} \\ R & =20 \mathrm{~m} \\ R & =30 \mathrm{~m}\end{aligned}$

(b)

FIGURE 11: (a) Changes in slip rate of outer track of slope steering at different steering radius on gault. (b) Changes in slip rate of inner track of slope steering at different steering radius on gault.

TABLE 2: Structural parameters of several tracked vehicles.

\begin{tabular}{|c|c|c|c|c|c|}
\hline Vehicle & $\begin{array}{l}\text { Vehicle mass } m \\
(\mathrm{~kg})\end{array}$ & $\begin{array}{c}\text { Tread of track } B \\
(\mathrm{~m})\end{array}$ & $\begin{array}{l}\text { Track-ground contact } \\
\text { Length } L(\mathrm{~m})\end{array}$ & $\begin{array}{l}\text { Height of vehicle centre of } \\
\text { gravity }(\mathrm{mm})\end{array}$ & $\begin{array}{l}\text { Track width } b \\
(\mathrm{~mm})\end{array}$ \\
\hline Tank $A$ & 36000 & 2640 & 3840 & 825 & 380 \\
\hline Tank $B$ & 42000 & 2800 & 4150 & 920 & 580 \\
\hline Tank $C$ & 50000 & 2790 & 5040 & 870 & 600 \\
\hline $\begin{array}{l}\text { Armoured vehicle } \\
A\end{array}$ & 21000 & 2810 & 4450 & 810 & 380 \\
\hline $\begin{array}{l}\text { Armoured vehicle } \\
B\end{array}$ & 28000 & 2840 & 5200 & 800 & 380 \\
\hline $\begin{array}{l}\text { Armoured vehicle } \\
\text { C }\end{array}$ & 14000 & 2620 & 3420 & 880 & 380 \\
\hline $\begin{array}{l}\text { Armoured vehicle } \\
D\end{array}$ & 13000 & 2550 & 3600 & 800 & 300 \\
\hline
\end{tabular}

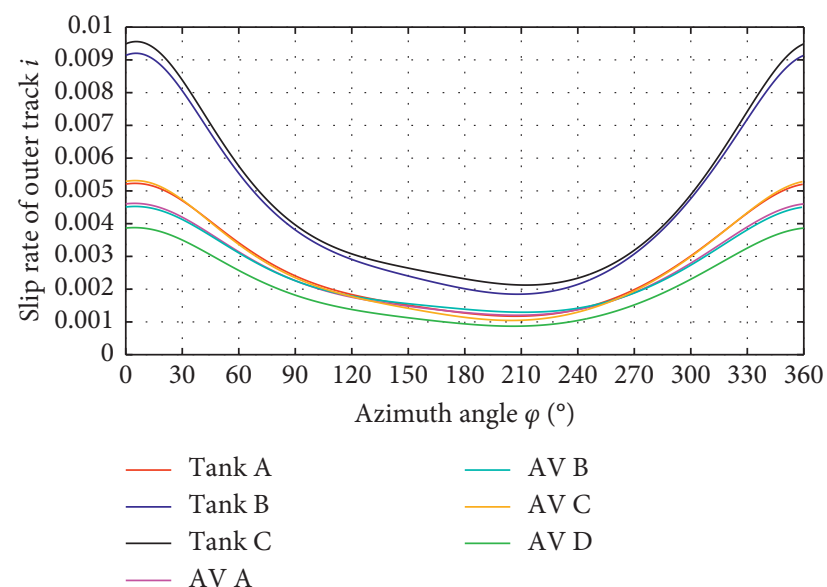

(a)
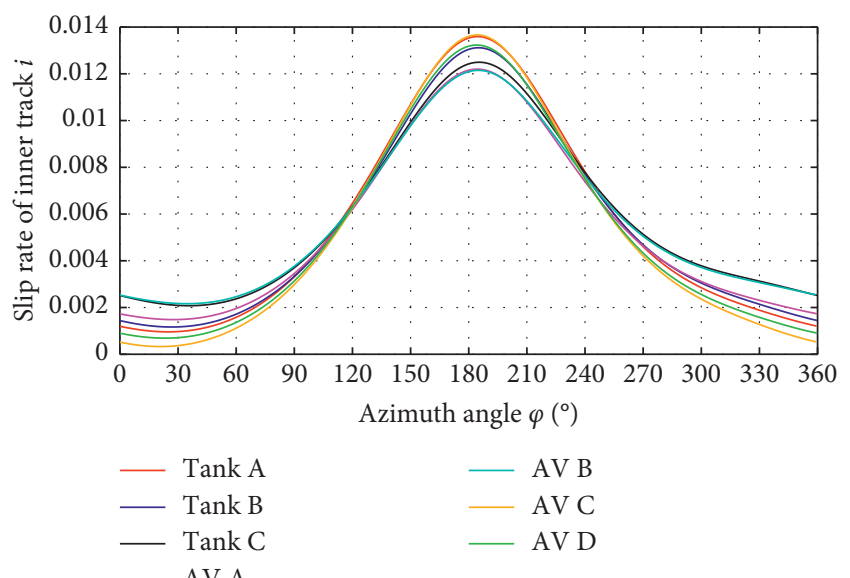

(b)

FIGURE 12: (a) Outer track slip rate comparison for different tracked vehicles. (b) Inner track slip rate comparison for different tracked vehicles. 


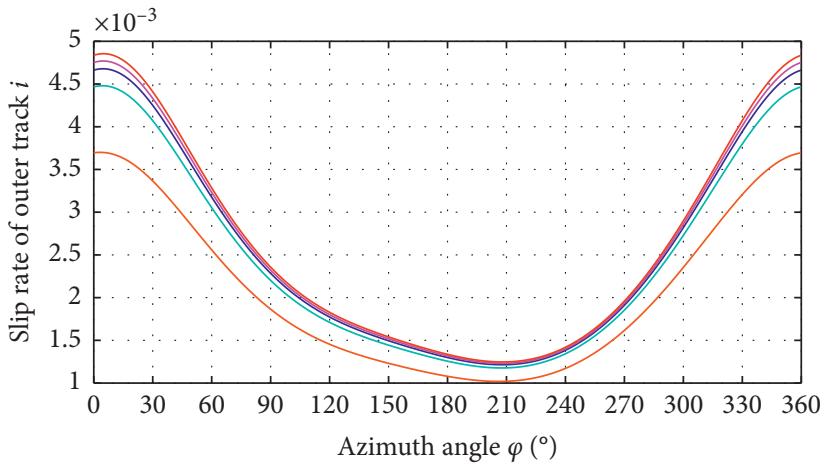

$m=55000 \mathrm{~kg}$
$-\quad m=35000 \mathrm{~kg}$
$m=25000 \mathrm{~kg}$

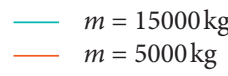

(a)

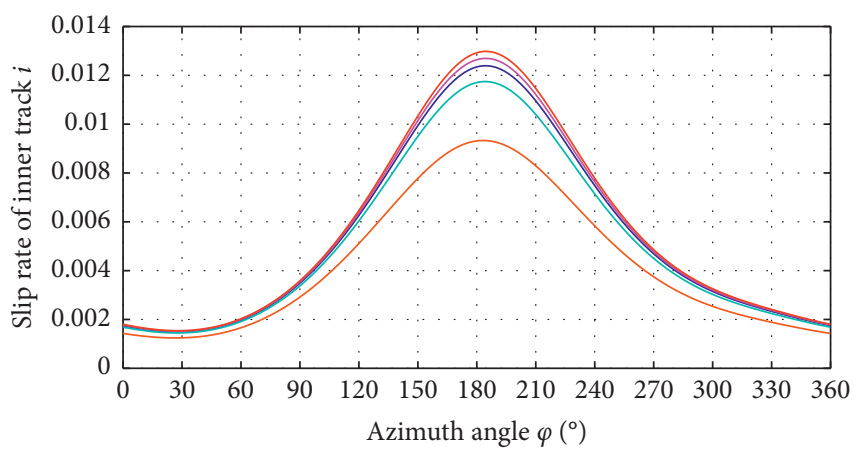

$m=55000 \mathrm{~kg}$
$-m=35000 \mathrm{~kg}$
$-m=25000 \mathrm{~kg}$

$-m=15000 \mathrm{~kg}$

$m=5000 \mathrm{~kg}$

(b)

FIGURE 13: (a) Outer track slip rate comparison at different vehicle mass. (b) Inner track slip rate comparison at different vehicle mass.

increase percentages of the outer track are $1.27 \%, 1.38 \%$, $3.19 \%$, and $15.5 \%$ and the increase percentages of the inner track are $25.88 \%, 5.52 \%, 2.43 \%$, and $2.26 \%$. Obviously, as the mass increases, the increase range decreases.

To evaluate the curves quantitatively, the curves are fitted and the slopes of curves are obtained. Therefore, variation trend of curves can be observed distinctly. Figure 14 shows the curves of slope values of slip rate curves of both tracks, and Table 3 shows the max and min slope values of both tracks at different vehicle mass.

4.2. Impact of Thread of Track on Tracked Vehicle Slope Steering Performance. We selected $B=2 \mathrm{~m}, B=2.5 \mathrm{~m}$, $B=2.81 \mathrm{~m}, B=3 \mathrm{~m}$, and $B=3.5 \mathrm{~m}$ for simulated analysis, with results shown in Figure 15.

Figures 15(a) and 15(b) show that as the thread of the track increases, the slip rates of both tracks decrease until the inner and outer tracks cannot achieve slope steering within the specified steering radius. When $B=2 \mathrm{~m}$, the curves of both tracks are incomplete, at an azimuth between $355^{\circ}$ and $20^{\circ}$, the outer track will completely skid; at an azimuth between $340^{\circ}$ and $5^{\circ}$, the inner track will completely skid. For slope steering performance, when the thread of the track is larger, the steering feature is better. Choose the min and max values to evaluate the variation trend of curves, the increase percentages of the outer track are $10.90 \%, 3.49 \%, 4.86 \%$, and $3.77 \%$ and the increase percentages of the inner track are $5.86 \%, 2.16 \%, 3.47 \%$, and $4.91 \%$. Obviously, as the thread increases, the decrease range is averaged nearly.

Figure 16 shows the curves of slope values of slip rate curves, and Table 4 shows the max and min slope values of both tracks at different threads of track.

\subsection{Impact of Track-Ground Contact Length on Tracked} Vehicle Slope Steering Performance. Track contact length of $L=3.5 \mathrm{~m}, L=4 \mathrm{~m}, L=4.45 \mathrm{~m}, L=5 \mathrm{~m}$, and $L=5.5 \mathrm{~m}$ was selected for simulation analysis, with results shown in Figure 17.

Figures 17(a) and 17(b) indicate that, for the inner track, the slip rate gradually increases in $\varphi=0 \sim 120^{\circ}$ and $240^{\circ} \sim 360^{\circ}$ and decreases gradually in $\varphi=120^{\circ} \sim 240^{\circ}$, as the track-ground contact length increases. The turn points are $\varphi=120^{\circ}$ and $\varphi=240^{\circ}$. For the outer track, the slip rate gradually decreases in $\varphi=0 \sim 120^{\circ}$ and $240^{\circ} \sim 360^{\circ}$ and increases gradually in the $\varphi=120^{\circ} \sim 240^{\circ}$ as the track-ground contact length increases. The turn points are the same as the inner track. Choose the min and max values to evaluate the variation trend of curves, the increase percentages of the outer track are 9.48\%, 5.62\%, 4.84\%, and $3.21 \%$ and the increase percentages of the inner track are $6.23 \%, 3.54 \%, 2.45 \%$, and $0.85 \%$. Obviously, as the length increases, the decrease range decreases.

Figure 18 shows the curves of slope values of slip rate curves, and Table 5 shows the max and min slope values of both tracks at different track-ground contact lengths.

\subsection{Impact of Height of CG on Tracked Vehicle Slope Steering} Performance. We selected $h=0.5 \mathrm{~m}, \quad h=0.75 \mathrm{~m}$, $h=0.81 \mathrm{~m}, h=0.9 \mathrm{~m}$, and $h=1 \mathrm{~m}$ for simulation analysis, with results shown in Figure 19.

Figures 19(a) and 19(b) show that as the height of CG increases, the slip rates of both tracks also increase. For the outer track, the main difference is obviously in $\varphi=0^{\circ} \sim 60^{\circ}$ and $\varphi=300^{\circ} \sim 360^{\circ}$. For the inner track, it is obviously in $\varphi=150^{\circ} \sim 240^{\circ}$. For UTVs, decreasing the height of CG would be beneficial to improve the slope steering performance on the premise of not affecting the trafficability of vehicle.

Choose the min and max values to evaluate the variation trend of curves, the increase percentages of the outer track are $0.48 \%, 0.42 \%, 0.49 \%$, and $0.84 \%$ and the increase percentages of the inner track are $2.63 \%, 1.94 \%, 1.87 \%$, and $2.36 \%$. Obviously, as the length increases, the increase range is averaged nearly.

Figure 20 shows the curves of slope values of slip rate curves, and Table 6 shows the max and min slope values of both tracks at different heights of CG.

\subsection{Impact of Track Width on Tracked Vehicle Slope Steering} Performance. We selected $b=0.1 \mathrm{~m}, b=0.3 \mathrm{~m}, b=0.38 \mathrm{~m}$, $b=0.58 \mathrm{~m}$, and $b=0.66 \mathrm{~m}$ for simulation analysis, with results shown in Figure 21. 


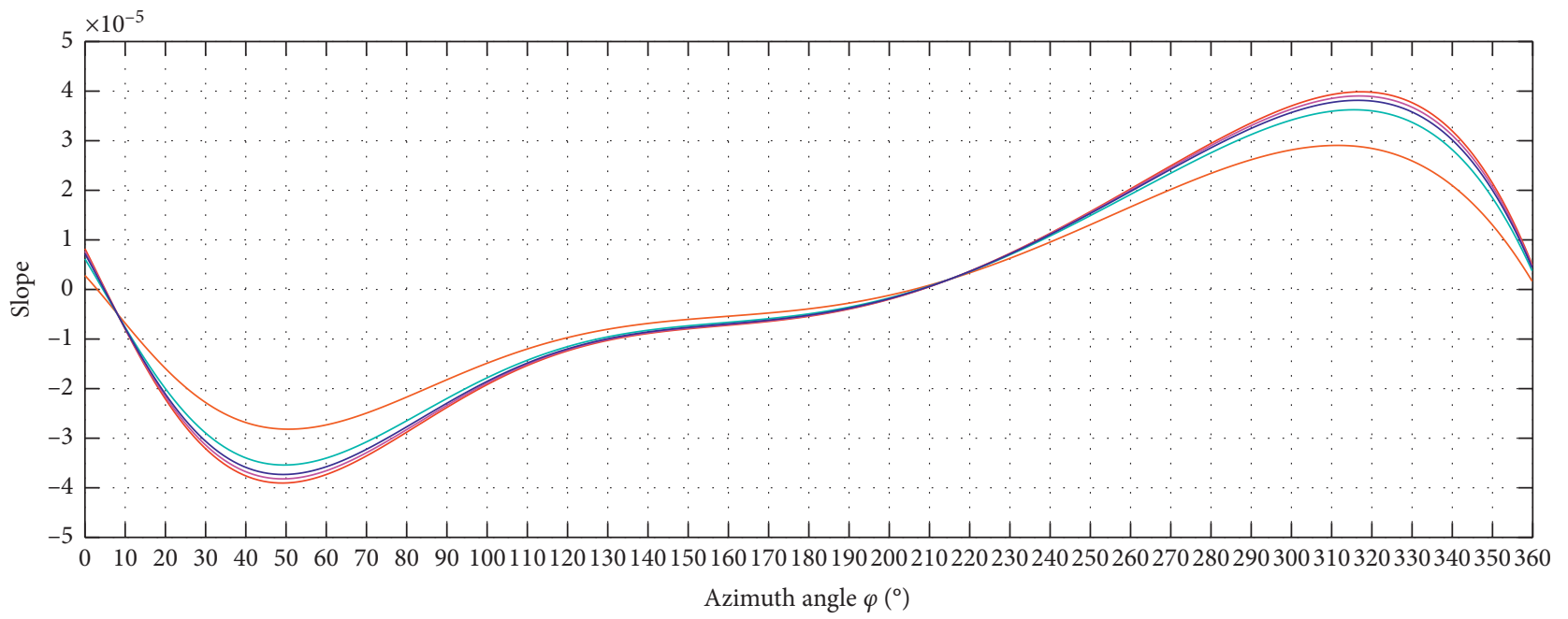
— $m=5000 \mathrm{~kg}$
— $m=15000 \mathrm{~kg}$
$\begin{aligned} m & =35000 \mathrm{~kg} \\ m & =55000 \mathrm{~kg}\end{aligned}$

(a)

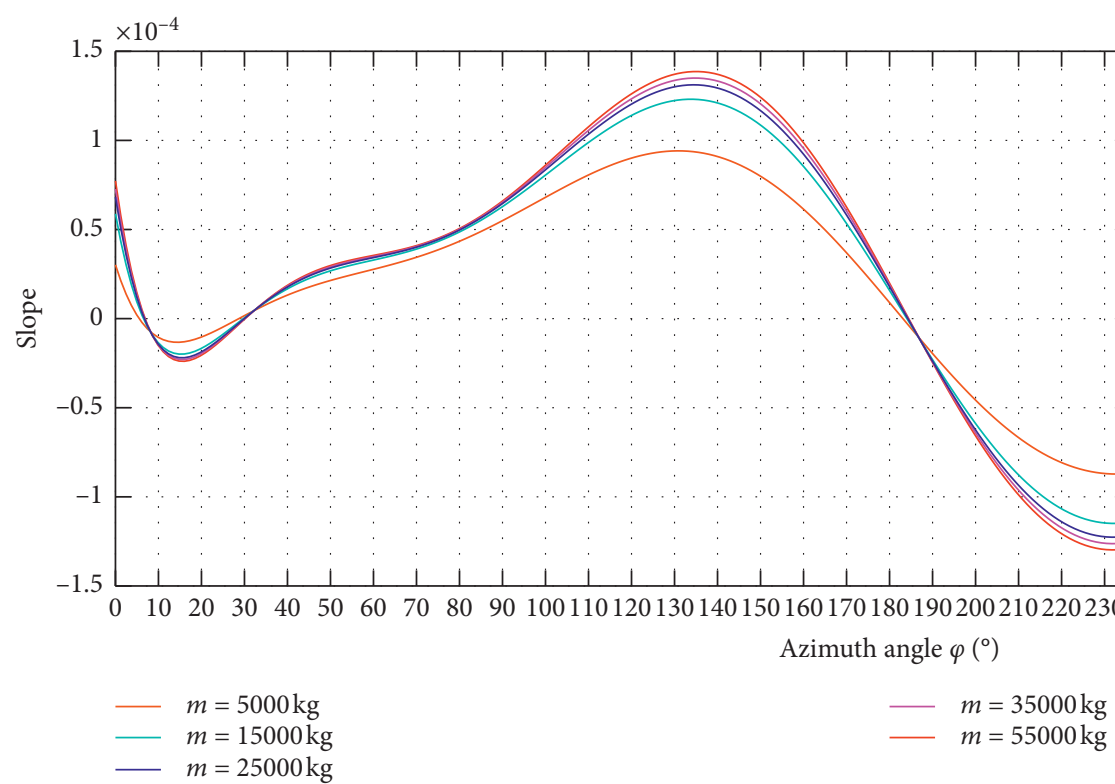

(b)

FIGURE 14: (a) Slope values of slip rate curves of outer track at different vehicle mass. (b) Slope values of slip rate curves of inner track at different vehicle mass.

TABLe 3: Max and min slope values of both tracks at different vehicle mass.

\begin{tabular}{lcccc}
\hline & \multicolumn{2}{c}{ Outer track/(10e-4)} & \multicolumn{2}{c}{ Inner track/(10e-4) } \\
& Max value & Min value & Max value & Min value \\
\hline$m=5000 \mathrm{~kg}$ & 0.2906 & -0.2818 & 0.9413 & -0.8722 \\
$m=15000 \mathrm{~kg}$ & 0.3624 & -0.3541 & 1.2308 & -1.1491 \\
$m=25000 \mathrm{~kg}$ & 0.3815 & -0.3732 & 1.3118 & -1.2264 \\
$m=35000 \mathrm{~kg}$ & 0.3903 & -0.3820 & 1.3479 & -1.2627 \\
$m=55000 \mathrm{~kg}$ & 0.3987 & -0.3904 & 1.3862 & -1.2976 \\
\hline
\end{tabular}




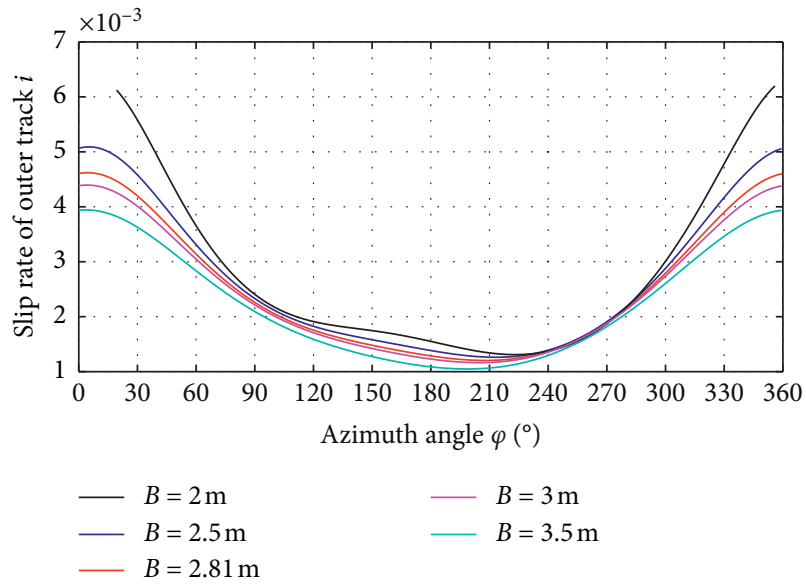

(a)

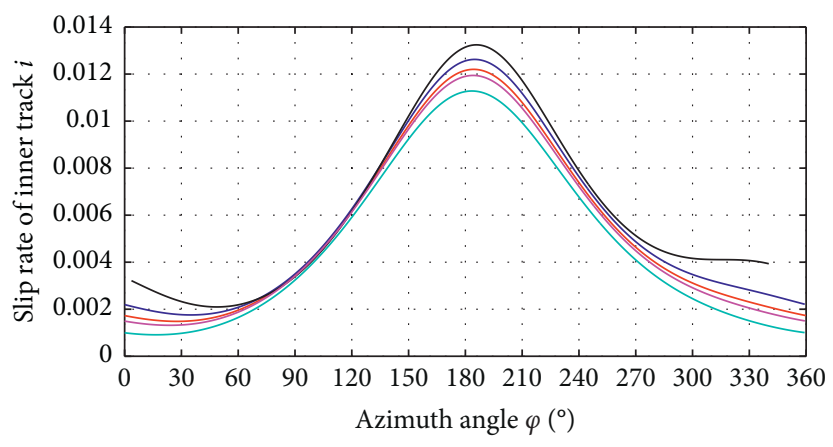

$\begin{aligned} B & =2 \mathrm{~m} \\ -B & =2.5 \mathrm{~m} \\ B & =2.81 \mathrm{~m}\end{aligned}$

(b)

FIGURE 15: (a) Outer track slip rate comparison for vehicle slope steering with different threads of track. (b) Inner track slip rate comparison for vehicle slope steering with different threads of track.

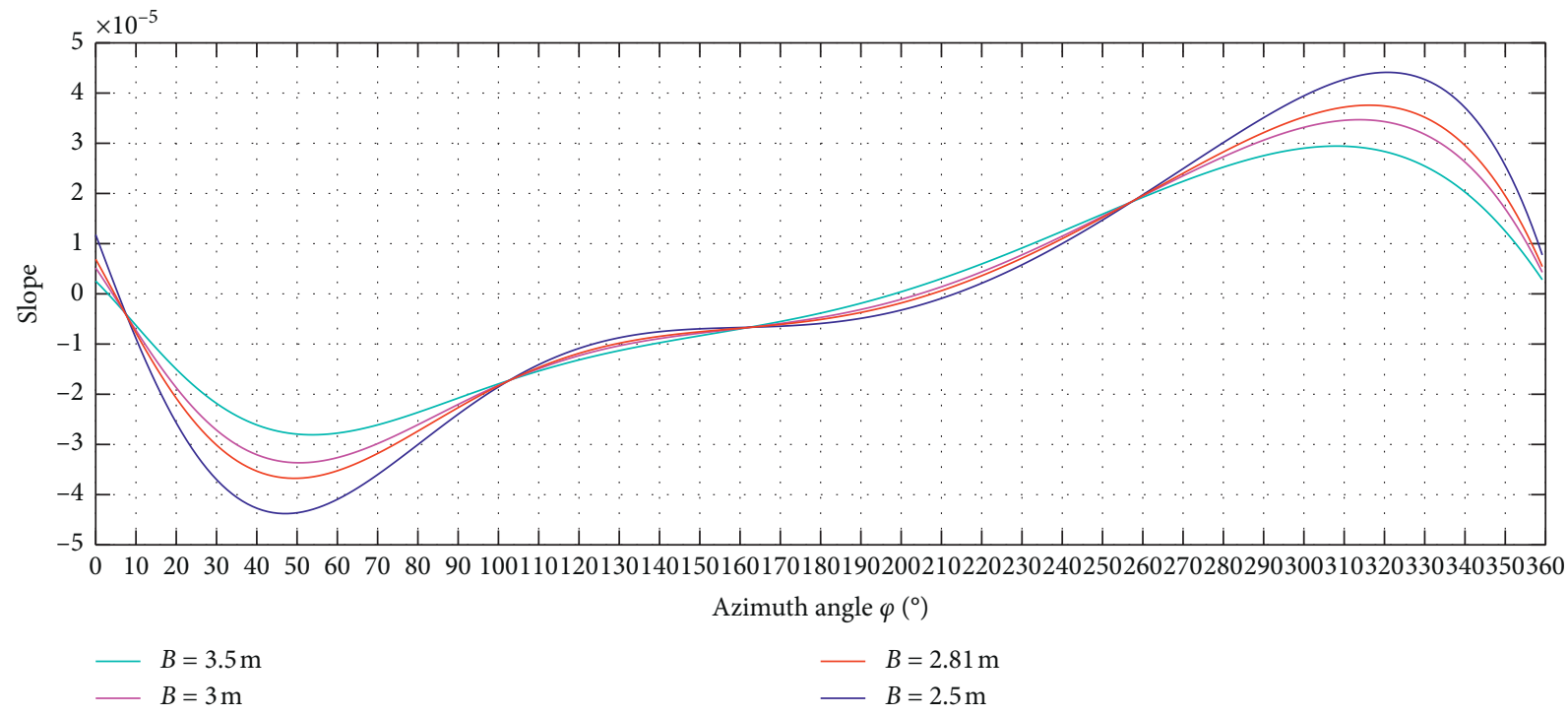

(a)

FIgURE 16: Continued. 


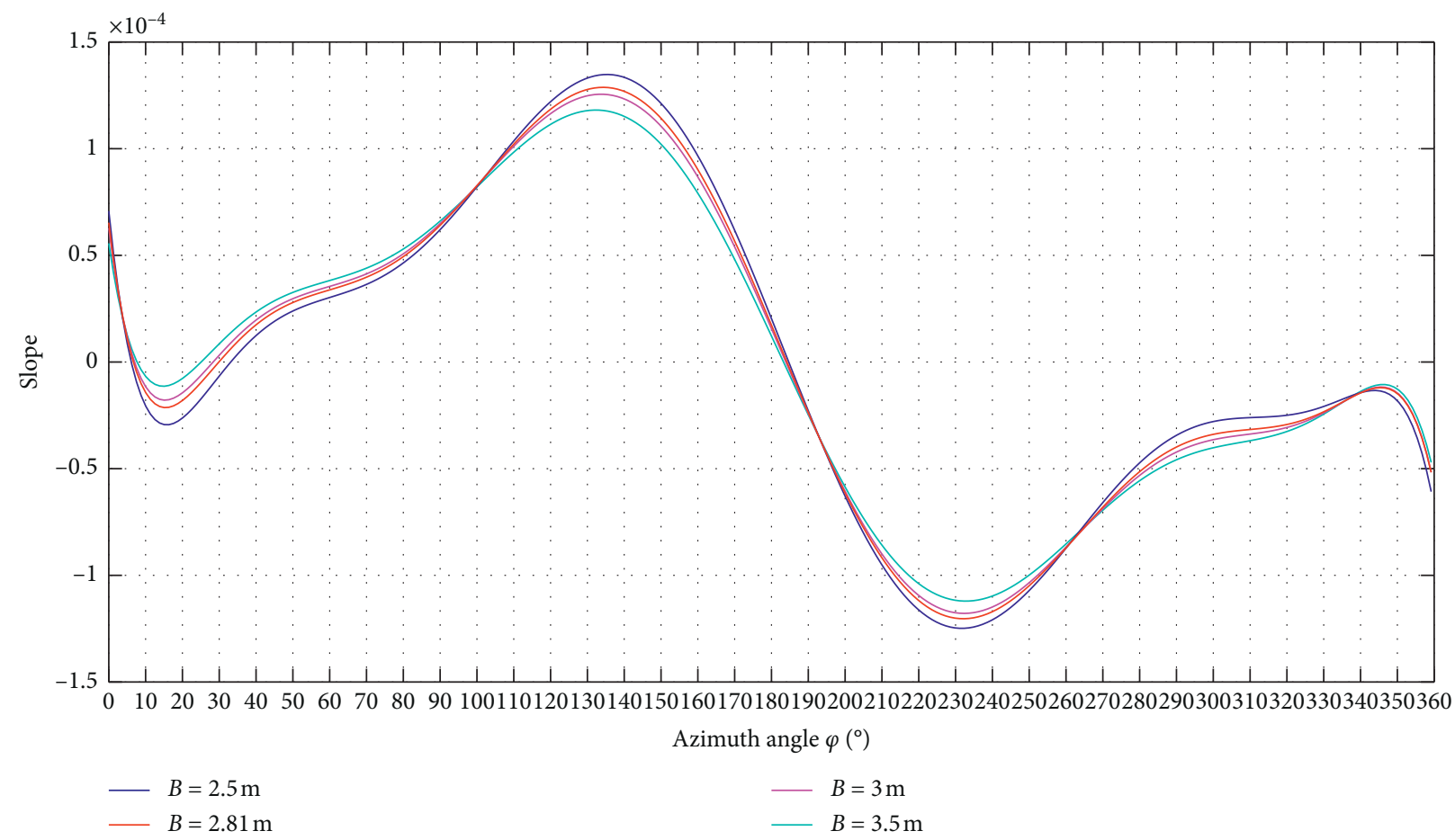

(b)

Figure 16: (a) Slope values of slip rate curves of outer track at different threads of track. (b) Slope values of slip rate curves of inner track at different threads of track.

TABle 4: Max and min slope values of both tracks at different threads of track.

\begin{tabular}{lcccr}
\hline & \multicolumn{2}{c}{ Outer track/(10e-4)} & \multicolumn{2}{c}{ Inner track/(10e-4) } \\
& Max value & Min value & Max value & -1.1811 \\
Min value \\
$B=2.5 \mathrm{~m}$ & 0.4413 & -0.4377 & 1.2552 & -1.2033 \\
$B=2.81 \mathrm{~m}$ & 0.3758 & -0.3675 & 1.2877 & -1.1784 \\
$B=3.5 \mathrm{~m}$ & 0.3470 & -0.3365 & 1.3479 & -1.1207 \\
\hline
\end{tabular}

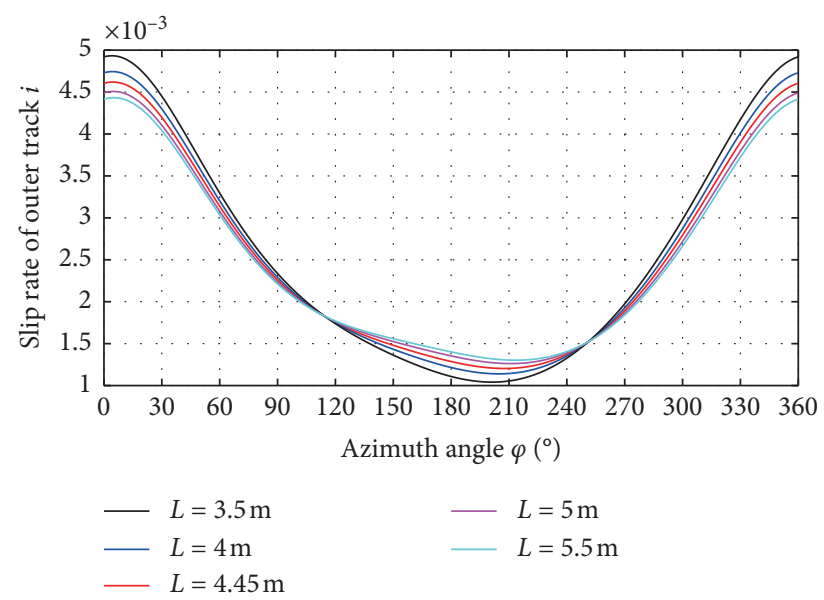

(a)

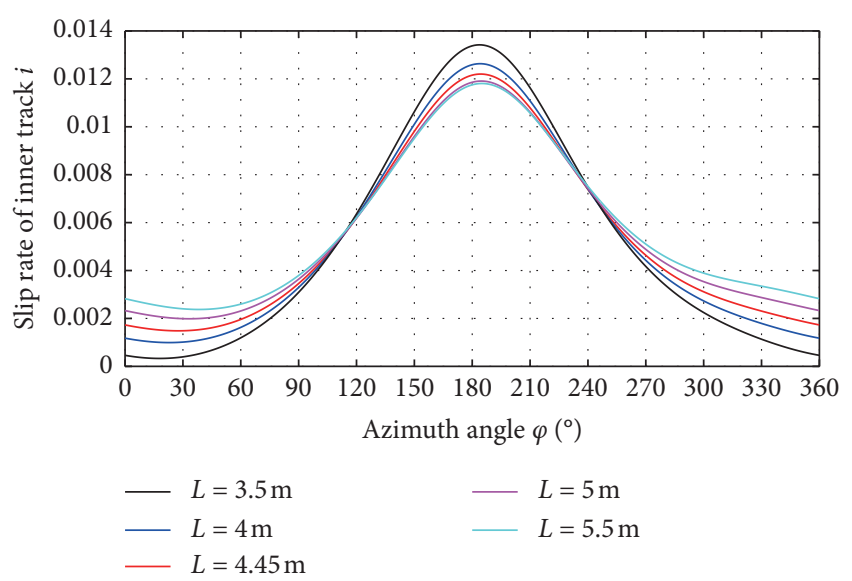

(b)

FIgURE 17: (a) Outer track slip rate comparison for slope steering with different track-ground contact lengths. (b) Inner track slip rate comparison for slope steering with different track-ground contact lengths. 


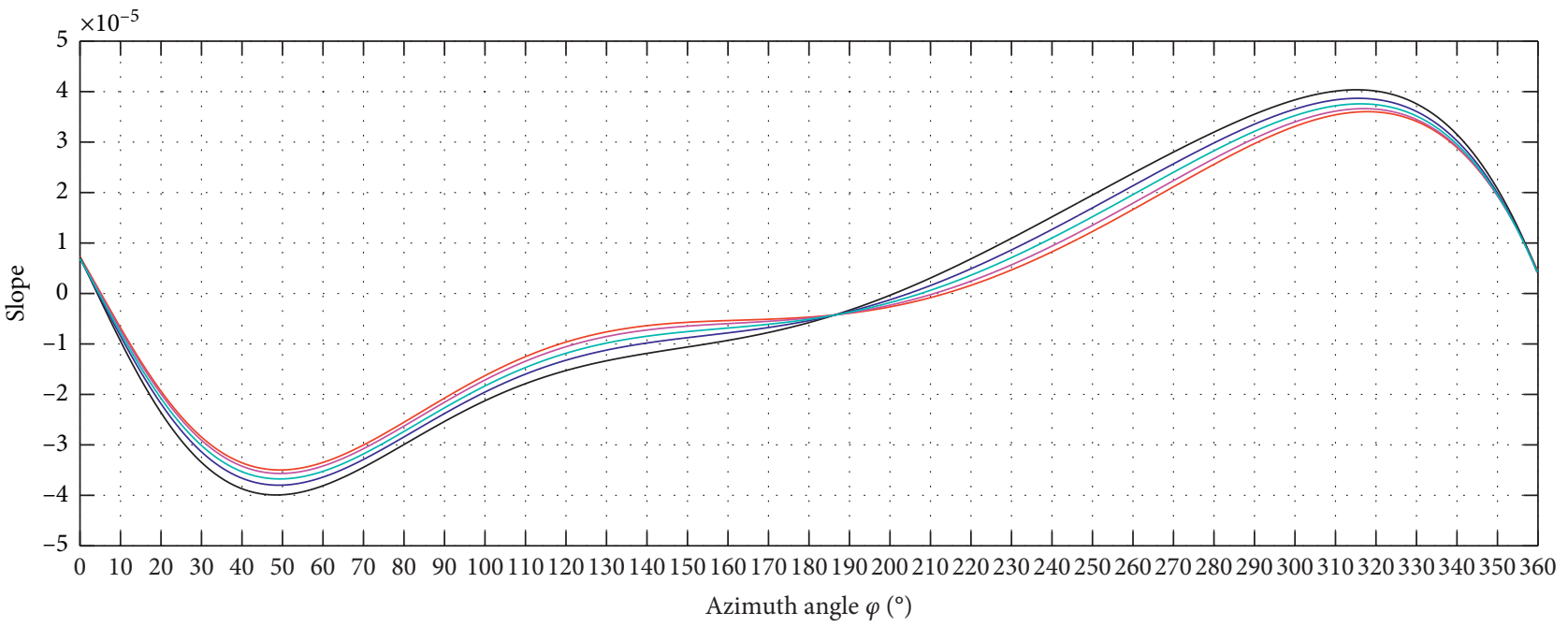
$-L=3.5 \mathrm{~m}$
- $L=4 \mathrm{~m}$
- $L=5 \mathrm{~m}$
$-L=4.45 \mathrm{~m}$
$-L=5.5 \mathrm{~m}$

(a)

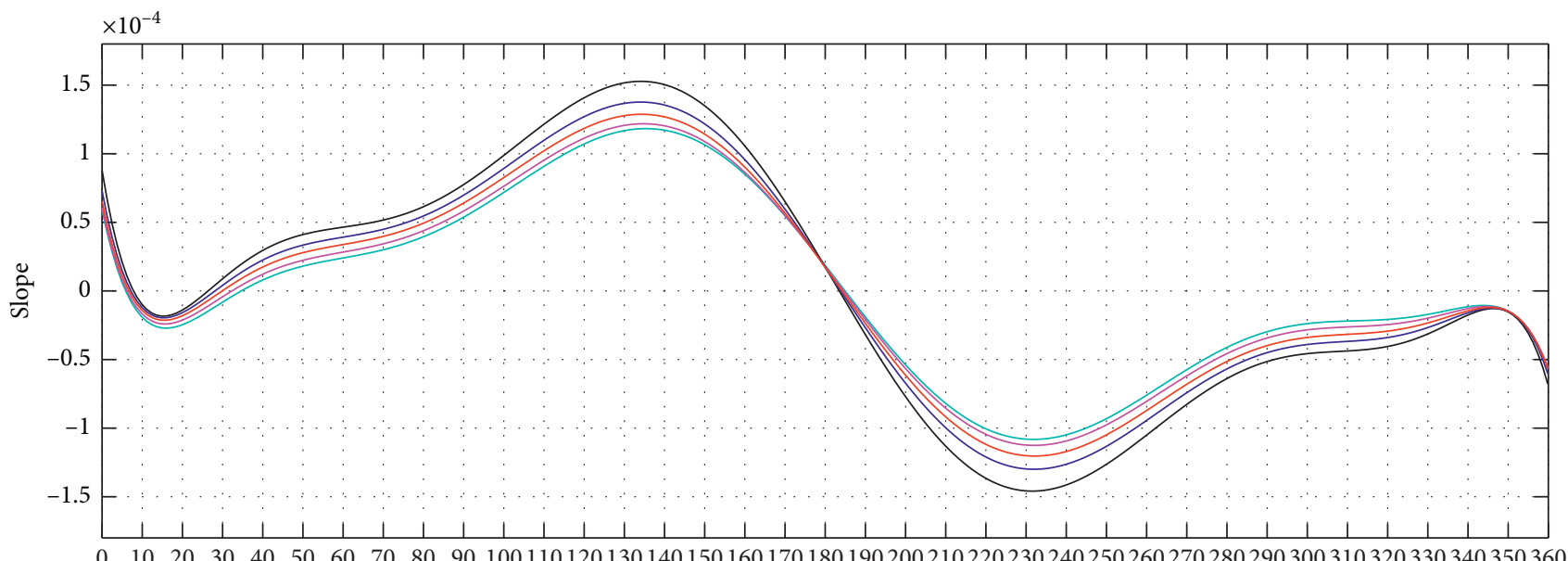

Azimuth angle $\varphi\left({ }^{\circ}\right)$

$$
\begin{aligned}
-L & =3.5 \mathrm{~m} \\
-L & =4 \mathrm{~m} \\
-L & =4.45 \mathrm{~m}
\end{aligned}
$$

$L=5 \mathrm{~m}$

$-L=5.5 \mathrm{~m}$

(b)

Figure 18: (a) Slope values of slip rate curves of outer track at different track-ground contact lengths. (b) Slope values of slip rate curves of inner track at different track-ground contact lengths.

TABLE 5: Max and min slope values of both tracks at different track-ground contact lengths.

\begin{tabular}{lcccr}
\hline & \multicolumn{2}{c}{ Outer track/(10e-4) } & \multicolumn{2}{c}{ Inner track/(10e-4) } \\
& Max value & Min value & 1.5277 & Min value \\
\hline$L=3.5 \mathrm{~m}$ & 0.4039 & -0.3993 & 1.3767 & -1.4591 \\
$L=4 \mathrm{~m}$ & 0.3868 & -0.3799 & 1.2877 & -1.2996 \\
$L=4.45 \mathrm{~m}$ & 0.3758 & -0.3675 & 1.2185 & -1.2033 \\
$L=5 \mathrm{~m}$ & 0.3663 & -0.3567 & 1.1831 & -1.1254 \\
$L=5.5 \mathrm{~m}$ & 0.3603 & -0.3498 & & \\
\hline
\end{tabular}




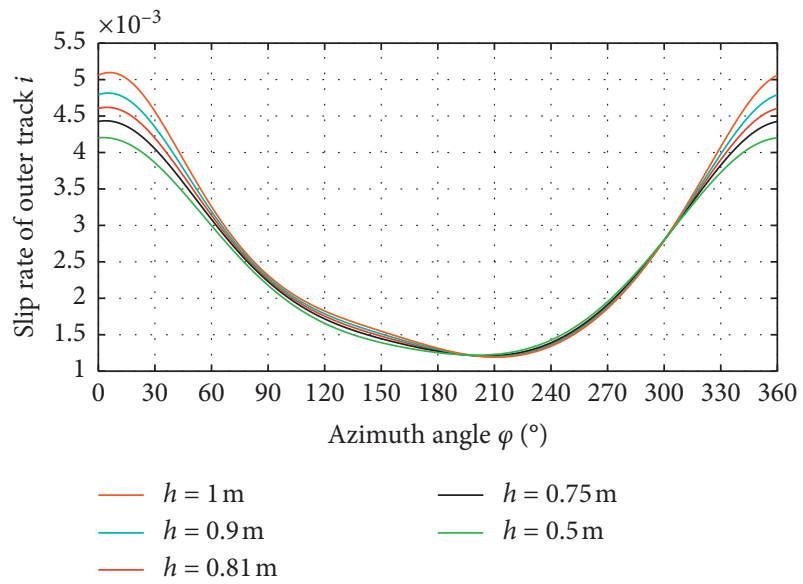

(a)

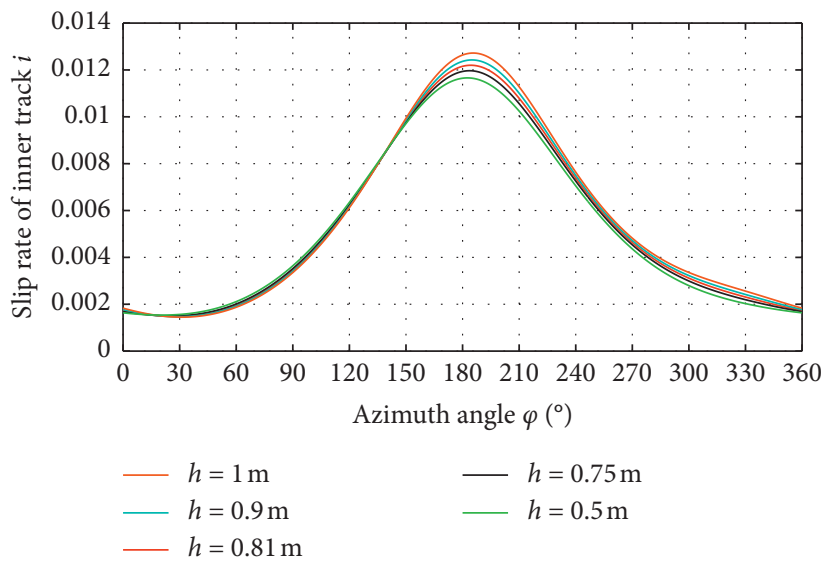

(b)

FIGURE 19: (a) Outer track slip rate comparison of vehicle slope steering with different heights of CG. (b) Inner track slip rate comparison of vehicle slope steering with different heights of CG.

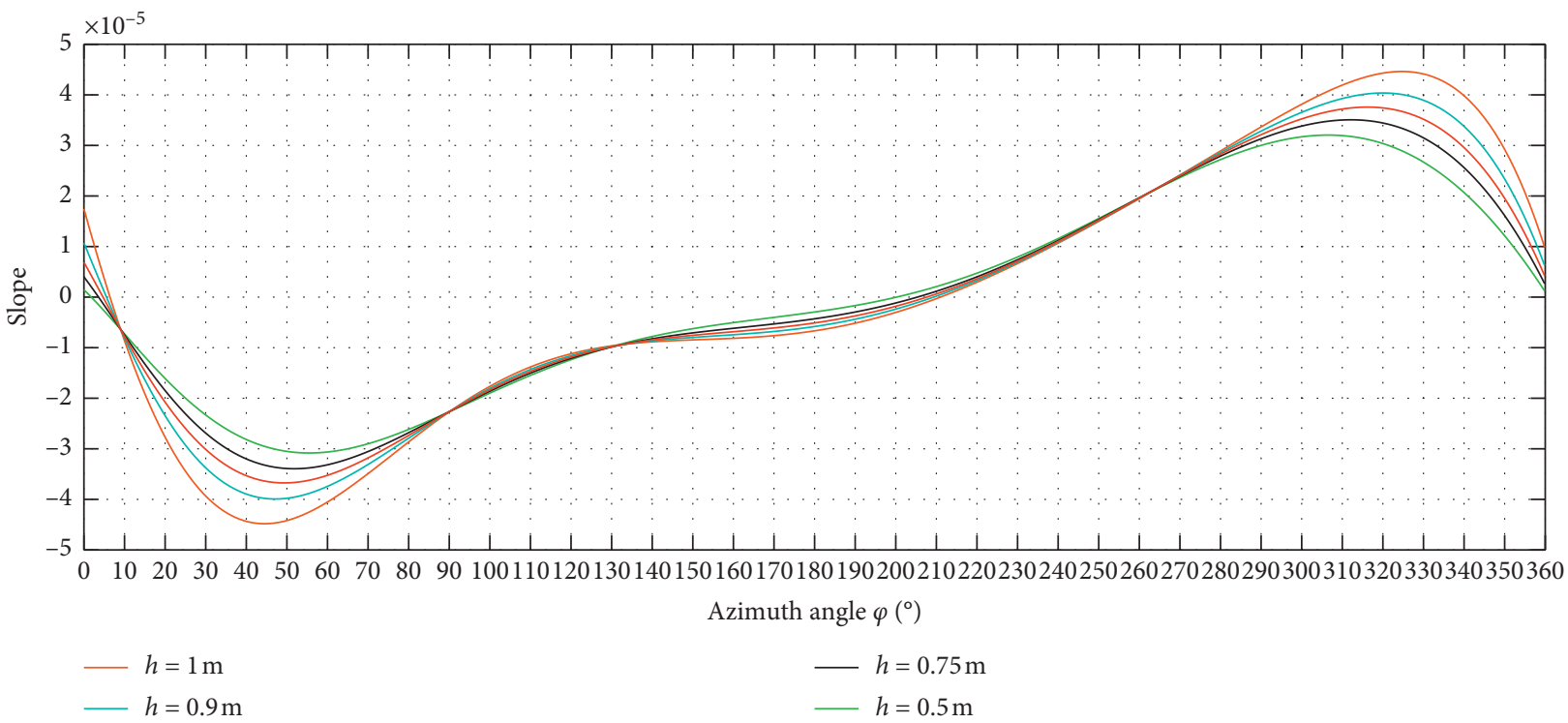

(a)

Figure 20: Continued. 


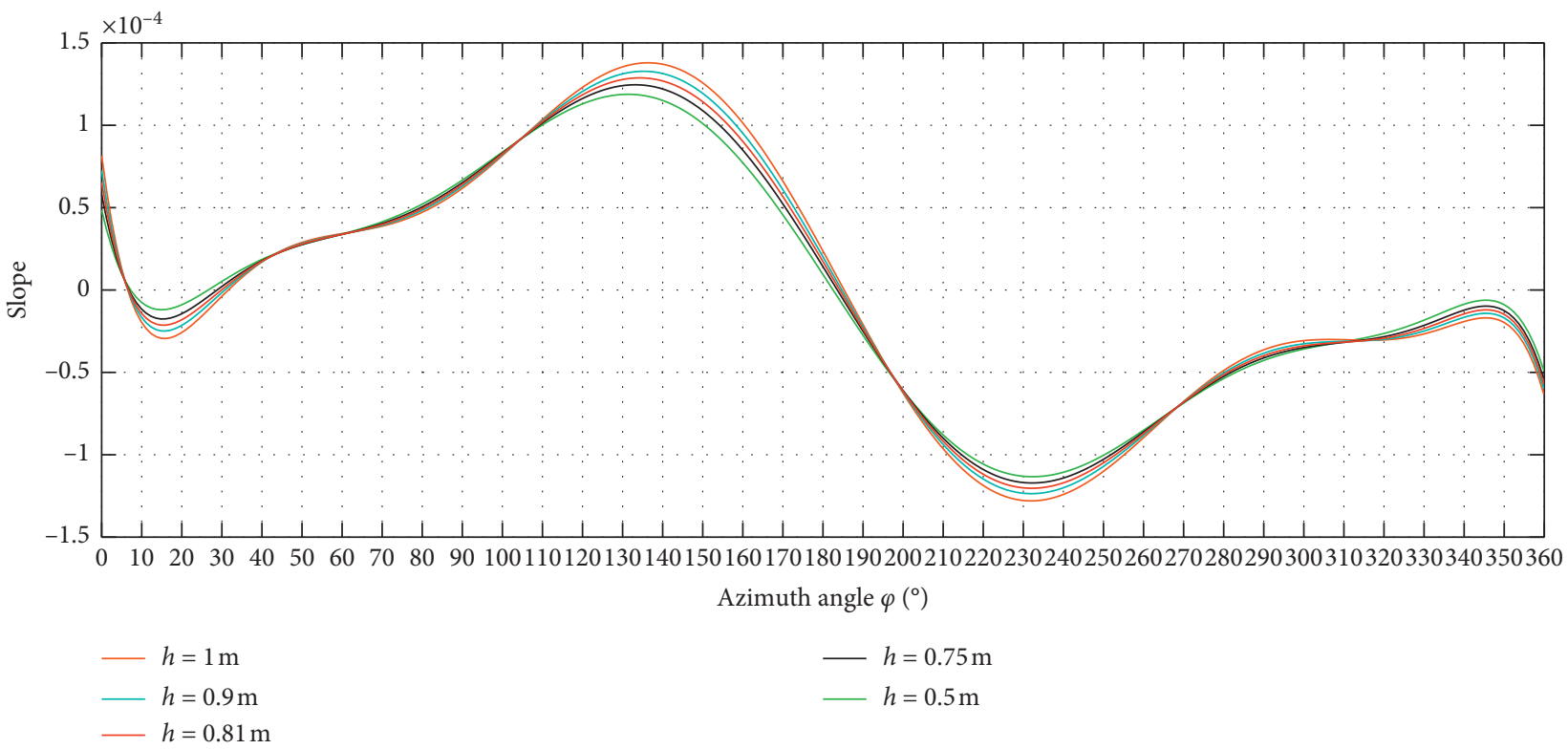

(b)

Figure 20: (a) Slope values of slip rate curves of outer track at different heights of CG. (b) Slope values of slip rate curves of inner track at different heights of CG.

TABle 6: Max and min slope values of both tracks at different heights of CG.

\begin{tabular}{lcccc}
\hline & \multicolumn{2}{c}{ Outer track/(10e-4) } & \multicolumn{2}{c}{ Inner track/(10e-4) } \\
& Max value & Min value & 1.3790 & Min value \\
\hline$h=1 \mathrm{~m}$ & 0.4462 & -0.4482 & 1.3277 & -1.2800 \\
$h=0.9 \mathrm{~m}$ & 0.4037 & -0.3993 & 1.2877 & -1.2361 \\
$h=0.81 \mathrm{~m}$ & 0.3758 & -0.3675 & 1.2485 & -1.2033 \\
$h=0.75 \mathrm{~m}$ & 0.3507 & -0.3395 & 1.1879 & -1.1711 \\
$h=0.5 \mathrm{~m}$ & 0.3205 & -0.3083 & & -1.1330 \\
\hline
\end{tabular}
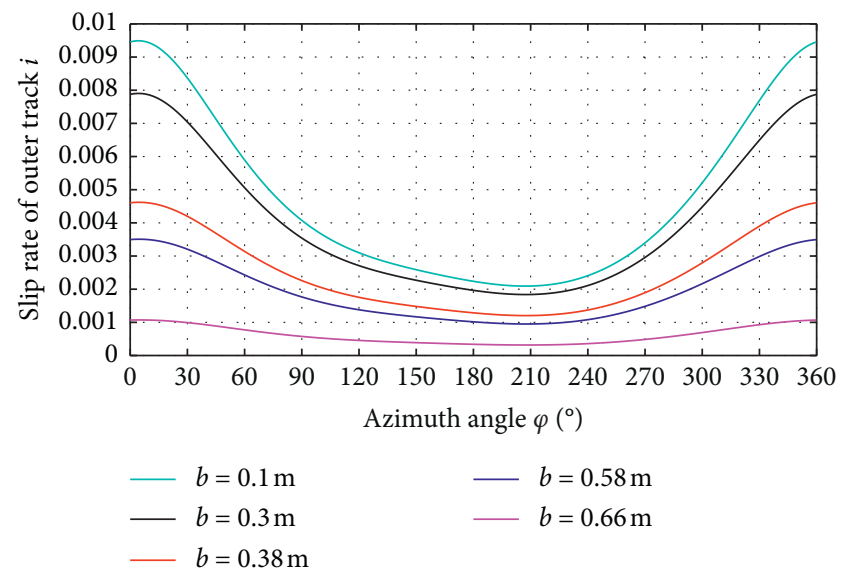

(a)

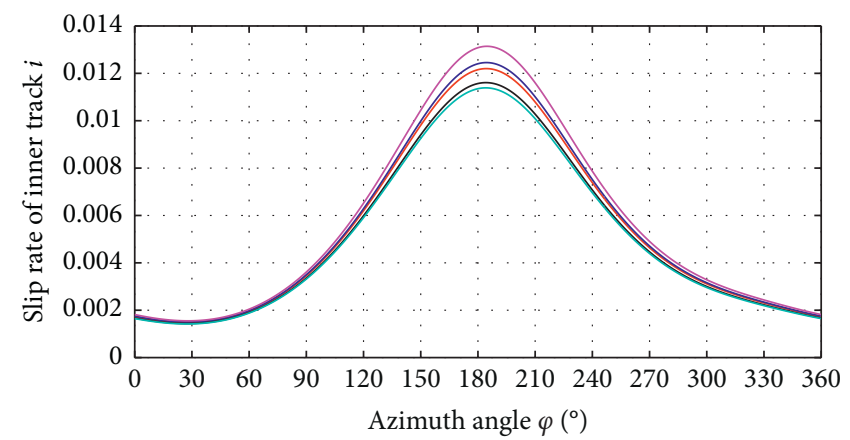

$\begin{aligned} b & =0.1 \mathrm{~m} \\ b & =0.3 \mathrm{~m} \\ b & =0.38 \mathrm{~m}\end{aligned}$

$-b=0.58 \mathrm{~m}$

$b=0.66 \mathrm{~m}$

(b)

FIGURE 21: (a) Outer track slip rate comparison for slope steering with different track widths. (b) Inner track slip rate comparison for slope steering with different track widths. 


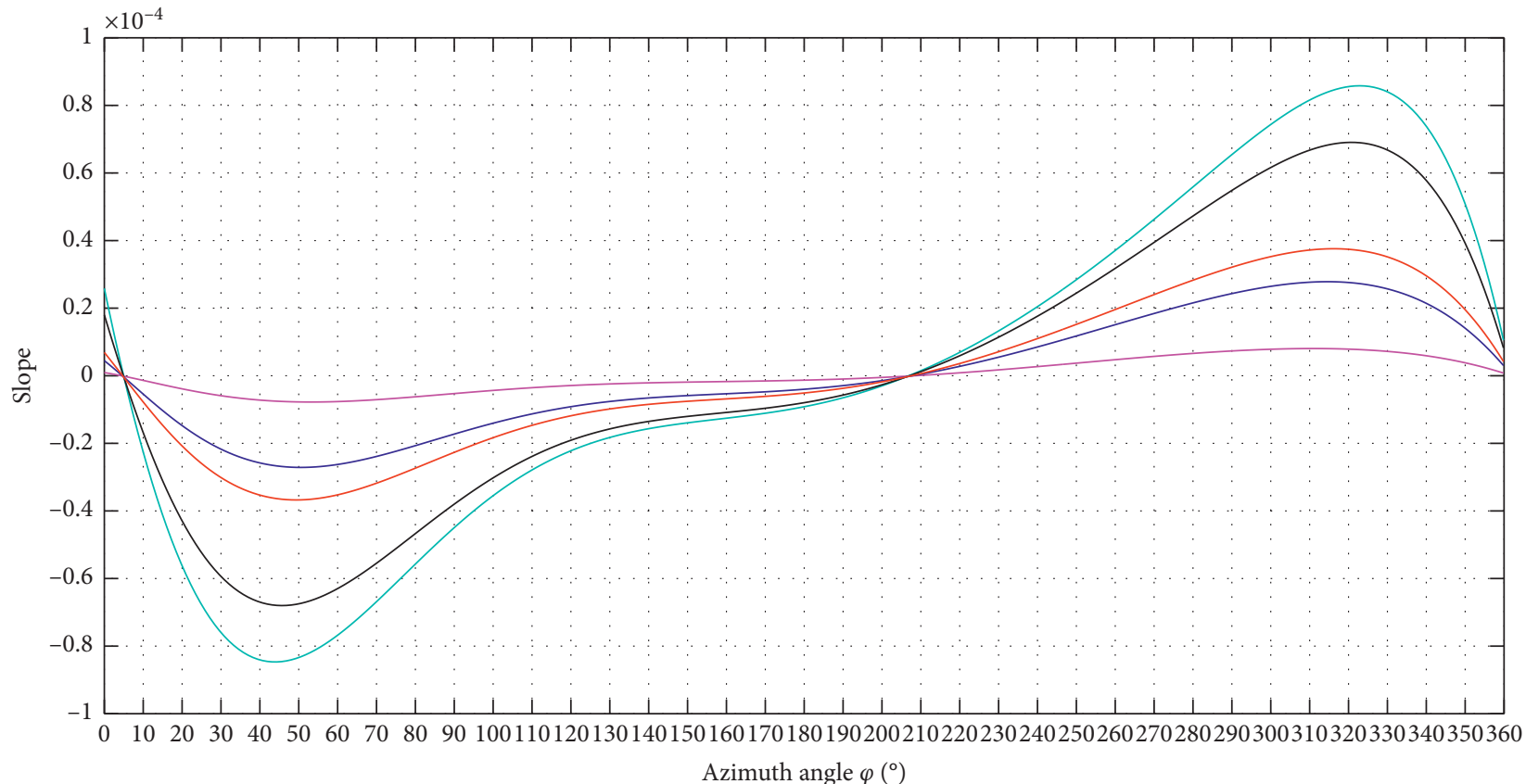
$-b=0.1 \mathrm{~m}$
$-b=0.3 \mathrm{~m}$
$-b=0.58 \mathrm{~m}$
$-b=0.38 \mathrm{~m}$

(a)

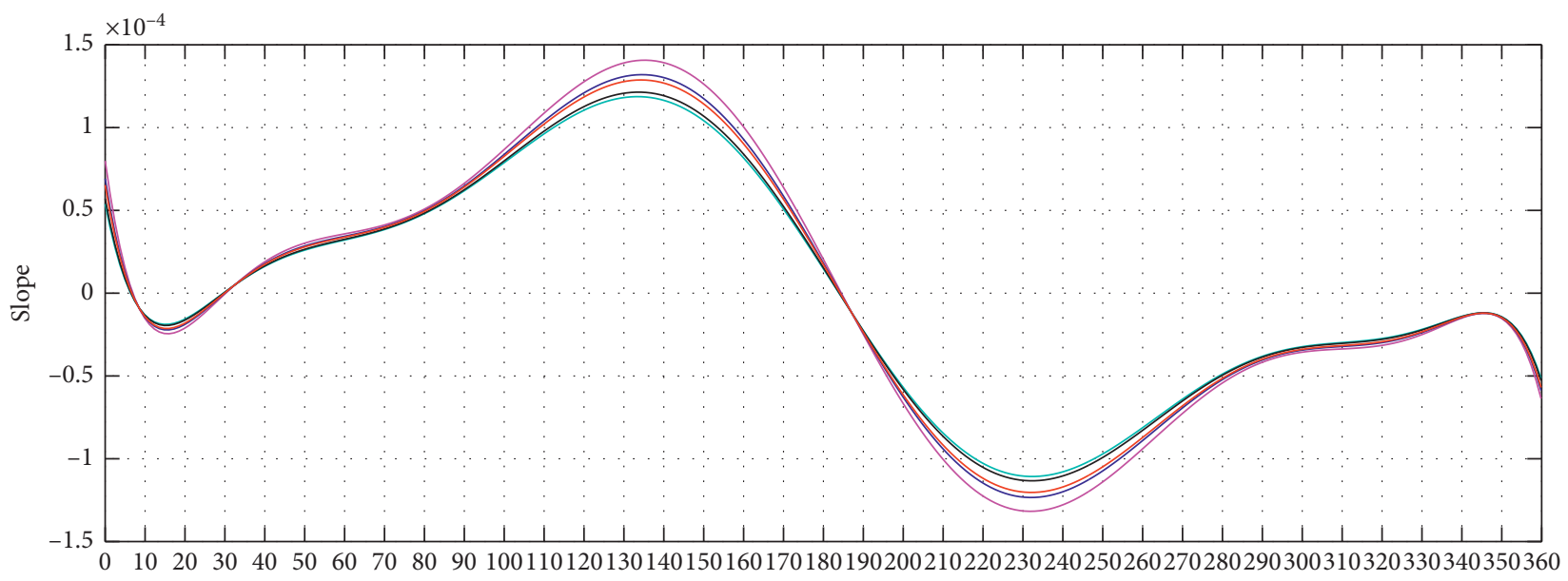

Azimuth angle $\varphi\left(^{\circ}\right)$
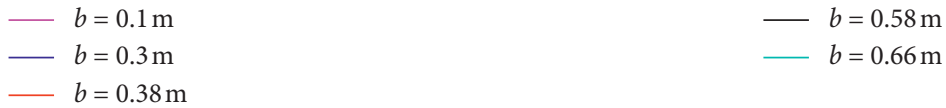

(b)

Figure 22: (a) Slope values of slip rate curves of outer track at different track widths. (b) Slope values of slip rate curves of inner track at different track widths.

As shown in Figures 21(a) and 21(b), the slip rate of the outer track increases gradually and the inner slip rate decreases gradually. The track width could increase the contact area, so as to improve vehicle trafficability. However, for the slope steering performance of UTVs, oversize width of track will augment the slip rate of outer track, even lead to totally skid. Choose the min and max values to evaluate the variation trend of curves, the increase percentages of the outer track are $0.48 \%, 0.42 \%$, $0.49 \%$, and $0.84 \%$ and the increase percentages of the 
TABLE 7: Max and min slope values of both tracks at different track widths.

\begin{tabular}{lcccc}
\hline & \multicolumn{2}{c}{ Outer track/(10e-4) } & \multicolumn{2}{c}{ Inner track/ $(10 e-4)$} \\
& Max value & Min value & Max value & Min value \\
\hline$b=0.1 \mathrm{~m}$ & 0.8580 & -0.0778 & 1.407 & -1.3174 \\
$b=0.3 \mathrm{~m}$ & 0.6906 & -0.2713 & 1.3196 & -1.2339 \\
$b=0.38 \mathrm{~m}$ & 0.3758 & -0.3675 & 1.2877 & -1.2033 \\
$b=0.58 \mathrm{~m}$ & 0.2783 & -0.6801 & 1.2139 & -1.1329 \\
$b=0.66 \mathrm{~m}$ & 0.0805 & -0.8468 & 1.1869 & -1.1070 \\
\hline
\end{tabular}

inner track are $1.93 \%, 5.1 \%, 2.09 \%$, and 5.52\%. Obviously, as the length increases, the increase range is averaged nearly.

Figure 22 shows the curves of slope values of slip rate curves, and Table 7 shows the max and min slope values of both tracks at different track widths.

With the augmenting of track width, the slip rate of the outer track gradually increases and the slip rate of the inner track gradually decreases. To enlarge the track width can augment the contact area, so as to improve the maneuverability of a vehicle. However, on a slope, to overly enlarge the width of the track will increase the slip rate of the outer track, possibly leading to overturning.

\section{Conclusion}

In this paper, an improved dynamic steering model is proposed when considering the shear stress-shear displacement relation of soil at the track-ground interface to investigate the slope steering performance of a tracked vehicle. The influence of ground characteristics, slope angle, and radius on the slope steering performance of a tracked vehicle is illustrated. Therefore, to make steering control strategy on the slope for the UTVs must consider about the angle of gradient and terrain conditions so as to plan corresponding steering velocity for both tracks, enabling vehicle get through field gradient terrain as the predetermined route with stability and high effectiveness.

The track slip rate is adopted as an index to evaluate the influence of typical vehicle structure parameters, heavy mass, thread of the track, and track-ground contact length, height of CG, track width, and on the slope steering performance of a tracked vehicle. Structural parameters must be fully considered when designing a UTV, especially for driving on loose slope terrain.

A major project for future research is to measure the characteristics of the ground and the slope angle by the sensors of UTV fusion online. The acquired parameters would be input to the dynamic model of tracked vehicle slope steering and help UTVs make path and motion planning.

\section{Data Availability}

The numerical data used to support the findings of this study are available from the corresponding author upon request.

\section{Conflicts of Interest}

The authors declare that there are no conflicts of interest regarding the publication of this article.

\section{Acknowledgments}

The authors acknowledge the support of the National Key R\&D Program of China (Grant no. 2018YFC0810500).

\section{References}

[1] H. Y. Chen, G. M. Xiong, J. W. Gong, and Y. Jiang, Introduction to Self-Driving Car, Beijing Institute of Technology Press, Beijing, China, 2014.

[2] Z. Liang, J. Zhao, Z. Dong et al., "Torque vectoring and rearwheel-steering control for vehicle's uncertain slips on soft and slope terrain using sliding model algorithm," IEEE Transactions on Vehicular Technology, vol. 69, no. 4, pp. 3805-3815, 2020.

[3] C. Zhang, Study on Dynamic Performance of Tracked Fire Fighting Robot, China University of Mining and Technology, Xuzhou, China, 2018.

[4] H.-Y. Liu, Analysis and Simulation of Micro-Crawer Hillside Tractor Perfoumamce, Northwest A\&F University, Xianyang, China, 2014.

[5] G. U. O. Xiao-lin, Driving Theory of Armored Vehicle, National Defense Industry Press, Beijing, China, 2014.

[6] Z. Zhang, Y. Fu-zeng, and J. Zhang, "Analysis on uniform steering of tracked vehicles on ramp," Tractor \& Farm Transporter, vol. 38, no. 6, pp. 44-48, 2011.

[7] Q. Shi and F. Sun, "Study on steering stability of tracked vehicles on ramp," Transactions of the Chinese Society for Agricultural Machinery, vol. 38, no. 7, pp. 22-26, 2007.

[8] F. Sun, Q. Shi, F. Guo, and Z. Li, "Performance of dynamics of tracked vehicles slope steering," China Mechanical Engineering, vol. 18, no. 22, pp. 2766-2771, 2007.

[9] Y. Qing-Dong, C. Hong-Wei, and L. Hong-Cai, "Performance of dynamics of tracked vehicles slope steering," Machinery Design \& Manufacture, vol. 12, no. 56, pp. 149-151, 2011.

[10] N. Xue, Research on Kinetics of the Tracked Vehicles and Weight Lightening for the Crawler Board, Hefei University of Technology, Hefei, China, 2016.

[11] H. Zhang, The Research of Turning Control on the Tracked Vehicle in the Deep-Sea Slope, Central South University, Changsha, China, 2010.

[12] F. Yue, Z. Wang, Y. Guo et al., "Overview of tracked vehicle steering performance for hilly areas," Hydraulics Pneumatics and Seals, vol. 9, no. 1, pp. 1-7, 2019.

[13] M. A. Wei-fang, H. Sun, and X. CHEN, "Impact of vehicular structure parameters on the steering performance of 6-track machines," Construction Machinery and Equipment, vol. 27, no. 11, pp. 11-14, 1996.

[14] W. Guo-Qiang, Y. Cheng, and M. A. Ruo-Ding, "Impact of structure parameters on articulated tracked vehicle's turning performance," Journal of Jilin University of Technology, vol. 27, pp. 7-12, 1997.

[15] C. Dong, K. Cheng, K. Hu, and W.-Q. Hu, "Dynamic modeling study on the ramp steering performance of articulated tracked vehicles," Advances in Mechanical Engineering, vol. 9, no. 7, pp. 1-26, 2017.

[16] R. Gonzalez and K. Iagnemma, "Slippage estimation and compensation for planetary exploration rovers. State of the art 
and future challenges," Journal of Field Robotics, vol. 35, no. 4, pp. 564-577, 2018.

[17] R. Zeng, Y. Kang, J. Yang et al., "Terrain parameters identification of kinematic and dynamic model for a tracked mobile robot," in Proceedings of the 4th Advanced Information Management,Communicates,Electronic and Automation Control Conference, pp. 575-582, Xi'an, China, 2018.

[18] J. O.-Y. Wong, Theory of Ground Vehicles, pp. 92-100, China Machine Press, Beijing, China, 2018.

[19] M. G. Bekker, Introduction to Terrain- Vehicle Systems, University of Michigan Press, Ann Arbor, MI, USA, 1969.

[20] J. Y. Wong, Terramechanics and Off-Road Vehicles, Elsevier Science, Amsterdam, Netherlands, 1989.

[21] J. Y. Wong and W. Huang, "Approaches to improving the mobility of military tracked vehicles on soft terrain," International Journal of Heavy Vehicle Systems, vol. 15, no. 2-4, pp. 127-151, 2008. 